Journal of Educational

and Psychological Sciences

Volume (5), Issue (43) : 30 Nov 2021

P: 89 - 107

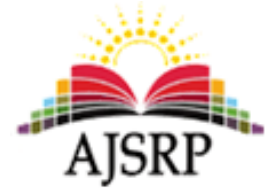

ISSN: 2522-3399

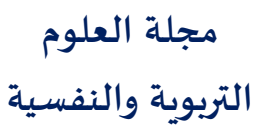

المجلد (5)، العدد (43) : 30 نوفمبر 2021 م

ص: 89 - 107

\title{
The effect of using tribal summaries of previous requirements on the development of educational attainment of second year secondary students in Biology subject in the Tabuk region
}

\begin{abstract}
Dhafer A Al-Qarni
Tabuk Education Directorate || Ministry of Education || KSA

Abstract: This study aimed at analyze the content of biology books for the secondary and intermediate stages to reveal the periods of interruption in presenting concepts related to the digestive system, endocrine glands and nutrition, and to provide a summary of these concepts before the process of teaching them. To achieve the objectives of the study, the researcher chose two secondary schools in an intentional manner and chose (98) students from them random manner, distributed among two divisions from each school, one experimental and the other as a control group. The members of the experimental group studied using the tribal summaries of the previous requirements, while the members of the control group studied in the traditional way. The researcher conducted an achievement test for the two groups. The results of the study showed that there was a break in teaching these concepts for more than 30 months, and also showed that the students of the experimental group outperformed the control group in the achievement test. Based on these results, the study recommends taking into account the principles of sequencing and continuity in teaching biology concepts in general, and the need to provide a summary before each study unit or lesson that addresses the previous concepts necessary for new learning.
\end{abstract}

Keywords: organizing the content of biology books, previous requirements, educational summaries strategy.

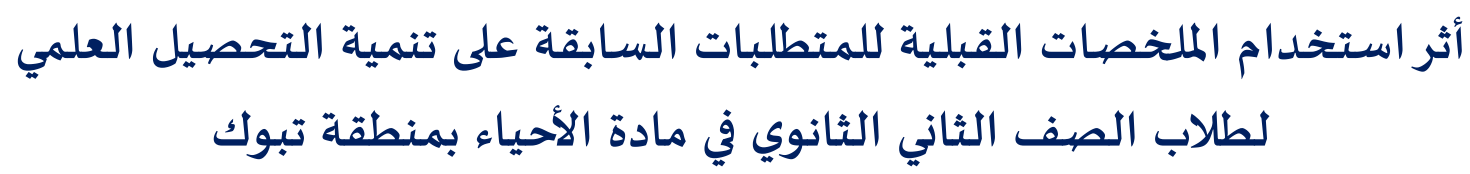

\author{
ظافر بن علي القرني \\ إدارة تعليم تبوك || وزارة التعليم || المملكة العربية السعودية اعرية
}

\begin{abstract}
المستخلص: هدفت هذه الدراسة إلى تحليل محتوى كتب الأحياء للمرحلتين الثانوية والمتوسطة للكشف عن فترات الانقطاع في عرض

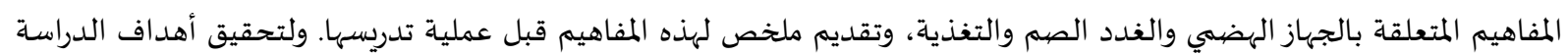

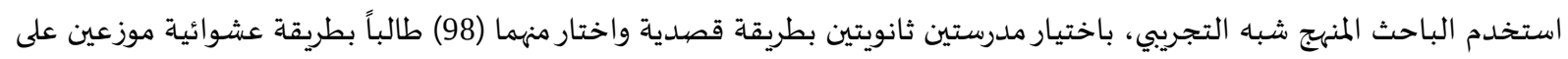
شعبتين من كل مدرسة إحداهما تجريبية وأخرى كمجموعة ضابطة، درس أفراد المجموعة التجريبية بطريقة المبادية الملخصيات القبلية

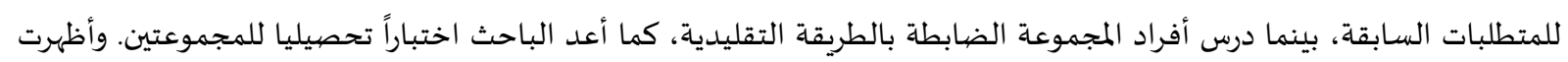

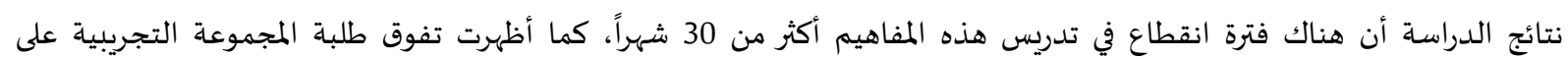

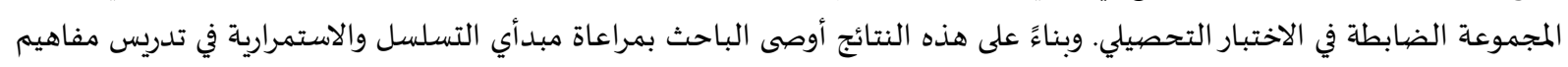
الأحياء بشكل عام، وضرورة تقديم ملخص قبل كل وحدة دراسية أو درس يعالج المفاهيم السابقة واللازمة للتعلم الجديد.

الكلمات المفتاحية: تنظيم محتوى كتب الأحياء، المتطلبات السابقة، استراتيجية الملخصيات التعليمية.
\end{abstract}


تسعى التربية الحديثة إلى إعداد أفراد المجتمع لمواجهة تحديات المستقبل عن طريق اكسابهم مهارات عقلية

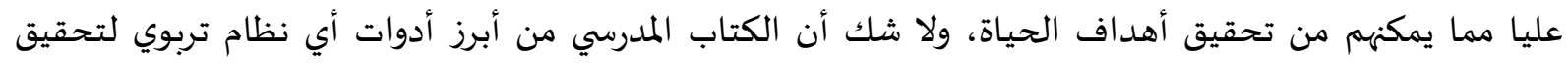

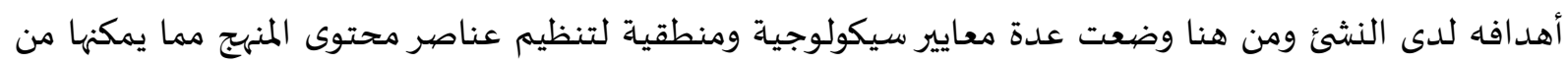
تحقيق الأهداف التي وضعت من أجلها.

فالمنهج الدراسي يعكس واقع المجتمع وفلسفته وثقافته وحاجاته وتطلعاته وهو الصورة التي تنفذ بها

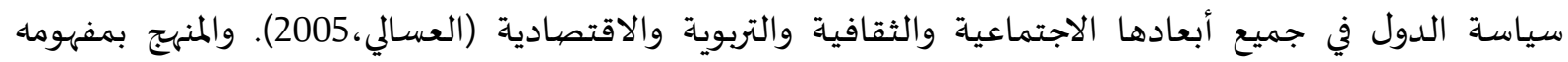

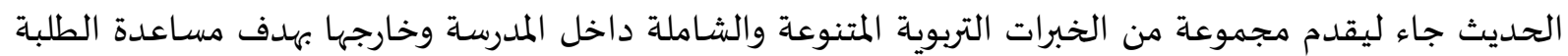

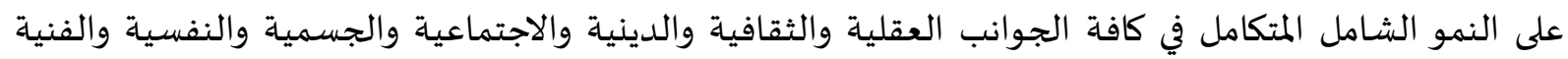
نمواً يكفل تفاعلهم بنجاح مع مجتمعاتهم (Colette,2001). تحتل كتب العلوم بشكل خاص مكانه متميزة فهي وسيله فاعلة وهامة من وسائل التعلم ونقل الثقافة

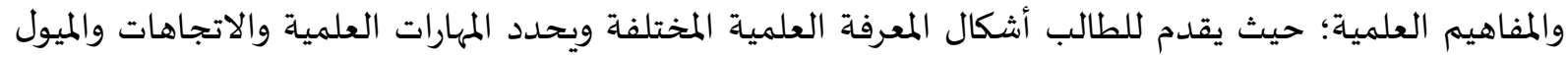
العلمية التي يؤمل من الطالب اكتسابها (Deng,2007). ولمسساعدة المناهج المدرسية على تحقيق ما وضعت من أجله لابد من مراعاة عدة معايير عند تنظيم محتواها

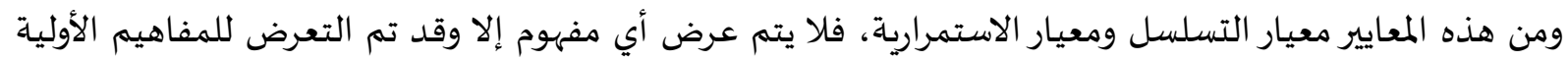

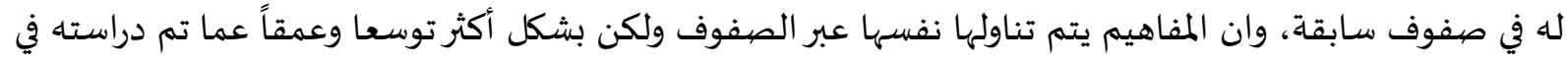
الصفوف السابقة.

مشكلة الدراسة:

من خلال مراجعة الأدب السابق تبين أن هناك تركيزاً على أهمية وجود توازن بين معياري التسلسل

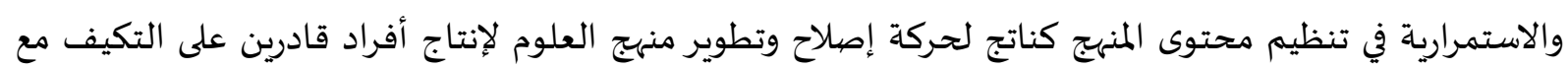

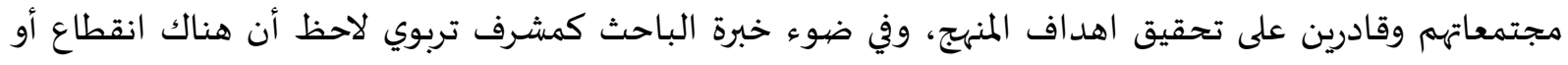

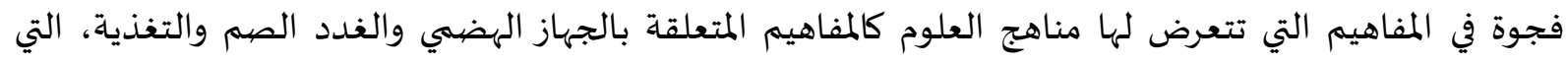

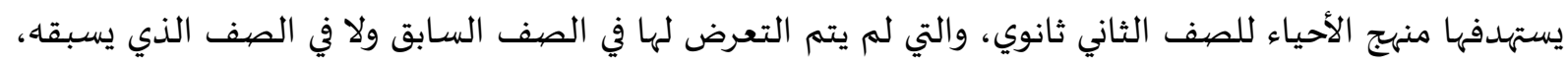

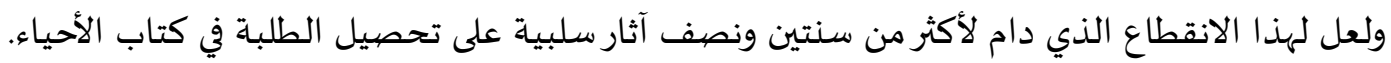

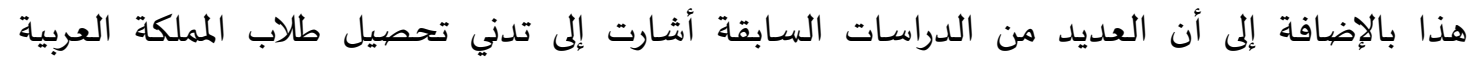

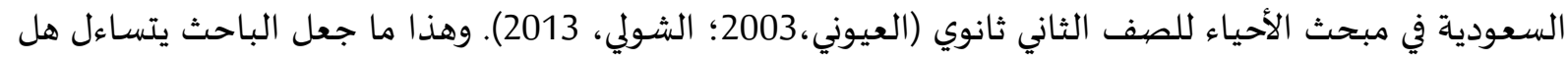
عدم مراعاة مبدأ الاستمرارية في عرض المفاهيم السابقة أثر على تدني تحصيل الطلبة؟ وهل تقديم ملخصيات للمفاهيم التي تم الانقطاع في تدريسها كمتطلبات سابقة سيحسن من تحصيل الطلبة في كتب الأحياء وبالتحديد تتحدد مشكلة الدراسة الحالية بالسؤال الرئيسي التالي:

ما أثر علاج الانقطاع في عرض مفاهيم الأحياء على تنمية تحصيل طلبة الصف الثاني باني ثانوي؟

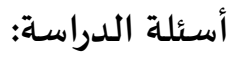

تتحدد مشكلة الدراسة في السؤال الرئيسي التالي: 
ما أثر استخدام الملخصات القبلية للمتطلبات السابقة على تنمية التحصيل العلمي لطلاب الصف الثاني

الثانوي في مادة الأحياء بمنطقة تبوك؟ مأفئ

ويتفرع عن هذا السؤال الأسئلة الفرعية التالية:

1- ما مدى تحقيق مبدأ التسلسل ومبدأ الاستمرارية في عرض مفاهيم (الجهاز الهضيهي، الغدد الصهم، التغذية)

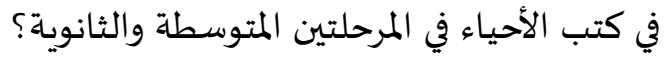

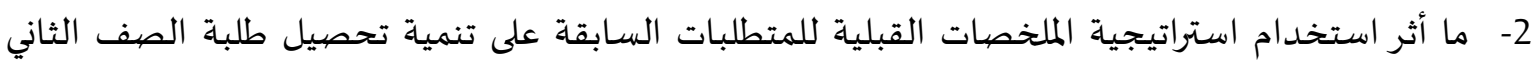

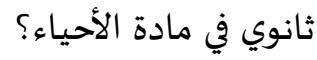

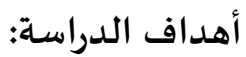

تهدف الدراسة الحالية إلى:

1. التعرف على مدى تحقيق مبدأ التسلسل ومبدأ الاستمرارية في عرض مفاهيم (الجهاز الهضيمي، الغدد الصهم،

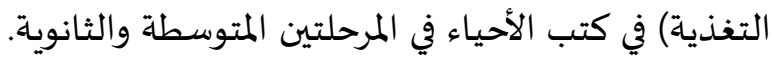

2. تقصي أثر استخدام استراتيجية الملخصات القبلية للمتطلبات السابقة على تنمية تحصيل طلبة المباء الصفئ

الثاني ثانوي في مادة الأحياء.

أهمية الدراسـة:

- - تسعى التربية إلى تمكين الافراد من تعليم أنفسهم وتنمية قدراتهم على كيفية اكتساب المعلومات المتطورة

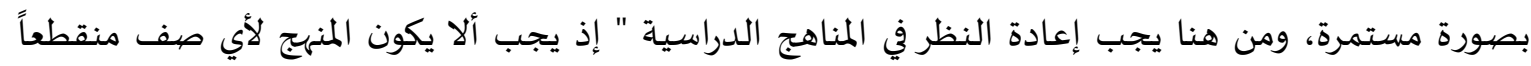

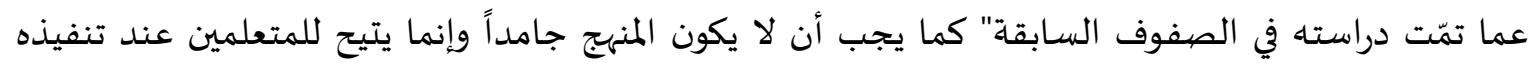

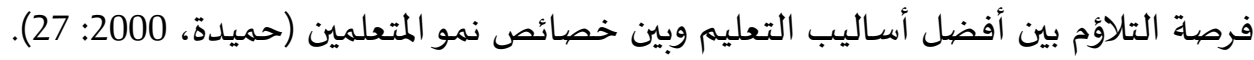

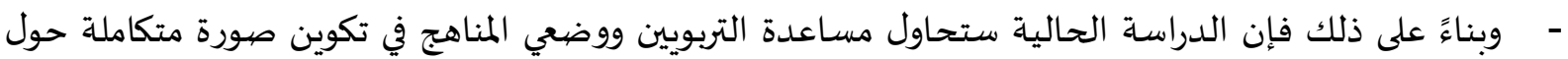

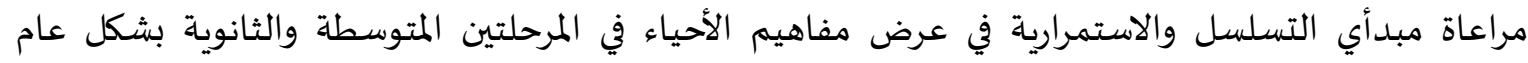

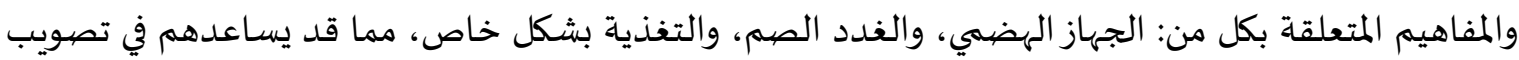

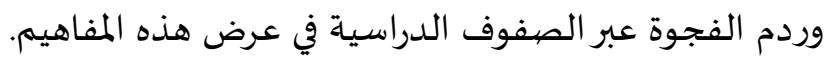
- كما أن هذه الدراسة ستساعد المعلم باعتباره وسيطاً بين المنهج والطالب باختيار طرائق تدريس مناسبة تساعده على استحضار المفاهيم التي تمت دراستها في صفوف سابقة واللازمة للتعلم للجديد.

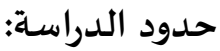

الحدود الموضوعية: اقتصرت الدراسة على محتويات الفصل السابع من مقرر الأحياء للصف الثاني ثانوي المطور من قبل شركة ماجروهل عام 2009م، وهي (الجهاز الهضيهي، الغدد الصهم، التغذية).

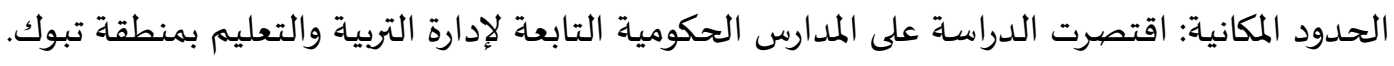
الحدود الزمانية: اقتصرت الدراسة على الفصل الدراسي الثاني للعام الدراسي 1435-1436هـ المداسئ

مصطلحات الدراسة: - التسلسل: عملية تنظيم للمحتوى الدراسي بحيث لا يتم عرض اي مفهوم او تعميم او مهاره او مسألة الا وقد تم عرض المفاهيم الاساسية له في مرحلة سابقة (سعادة وابراهيم ، 2008). 
O ويعرفه الباحث إجرائياً: بأنه هو عبارة عن تنظيم المحتوى الدراسي لعرض مفاهيم الأحياء على تنمية تحصيل طلبة الصف الثاني ثانوي. - - الاستمرارية: يقصد بها وجود علاقة رأسية بين عناصر المنهج بحيث تراعى فهيها المرحلة النمائية للمتعلم جسمياً

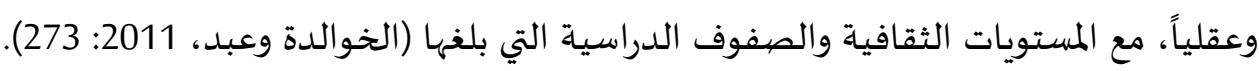

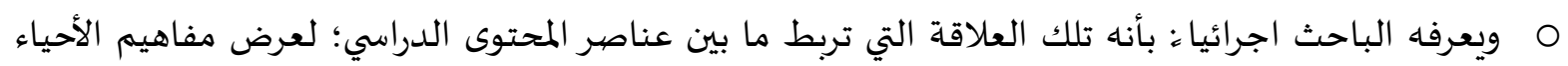

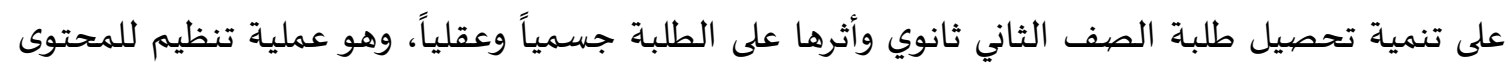

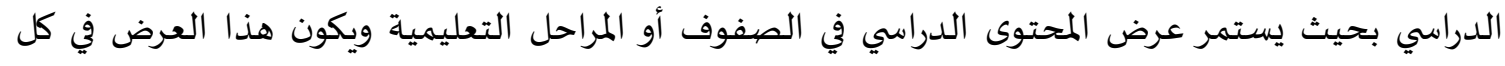

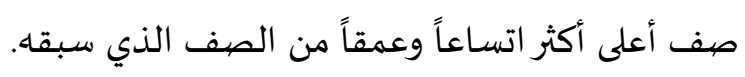

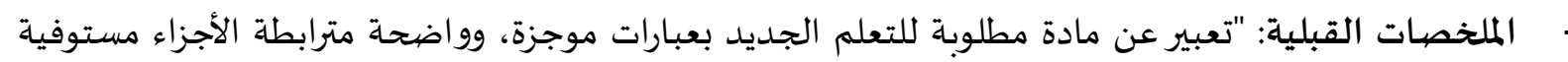

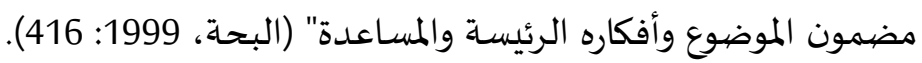

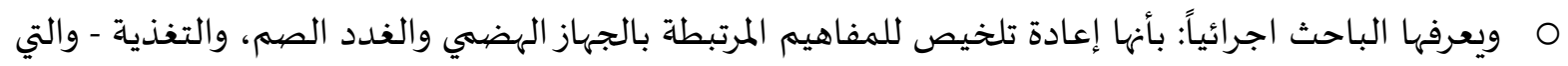

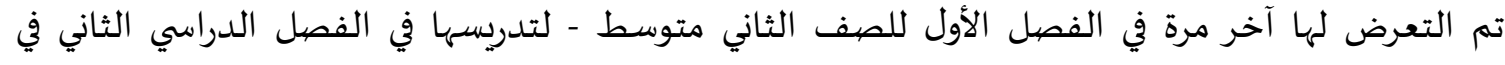

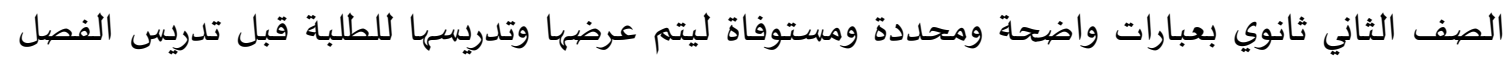

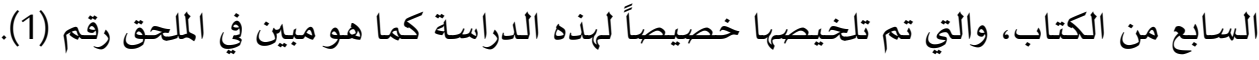
- التحصيل: " مدى استيعاب الطلاب لما تلقوه من خبرات معينة خلال مقررات دراسية معينة "(العبيدي، 2007:

O ويعرفها الباحث اجرائياً: بالدرجة الكلية التي سيحصل علهها الطلاب في اختبار التحصيل الذي أعد خصيصا

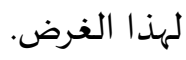

2. الإطار النظري والدراسات السابقة. بالرغم من الجهود المبذولة من قبل المعلمين والمشرفين التربويين مع المؤسسات المعنية بالعملية التعليمية المبادية

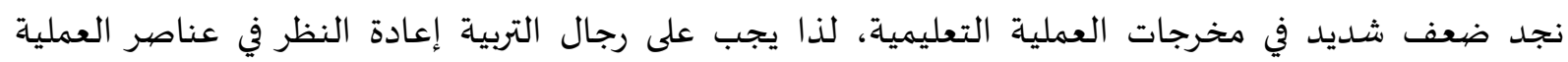

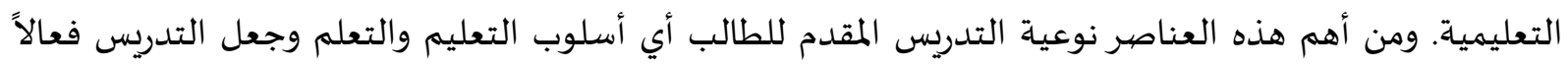

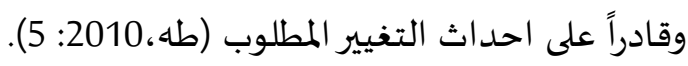

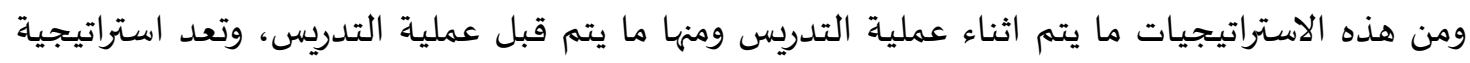

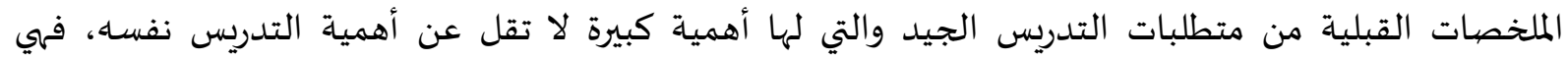

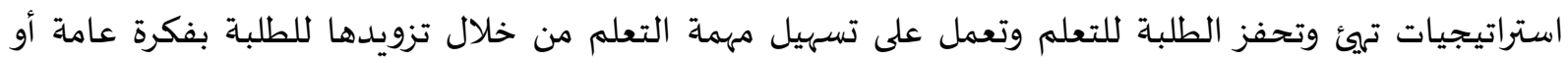
منظور شامل للمفاهيم التي درسها سابقاً واللازمة للتعلم الجديد التيد.

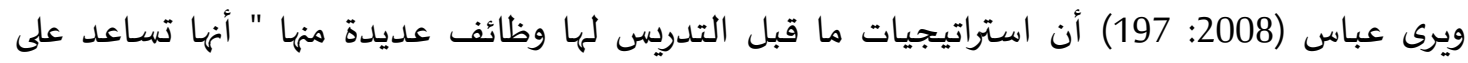

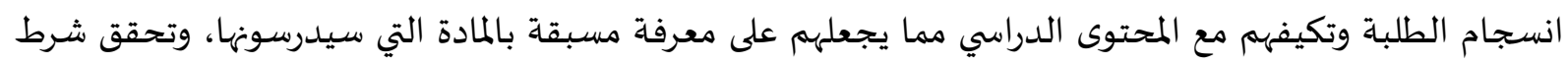

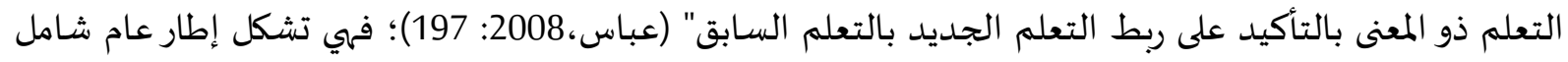

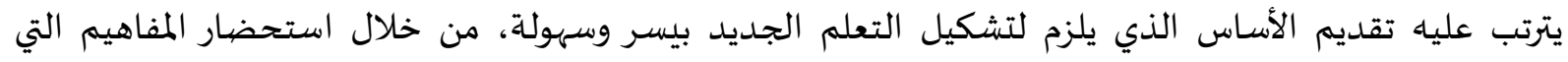

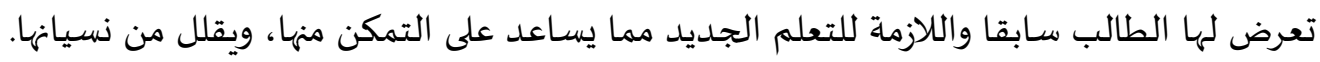
ويشير الأدب التربوي السابق إلى وجود ست استراتيجيات قبلية للتدريس هي: (العاني،2002؛ النعيهي،2006؛

عباس،2008) 


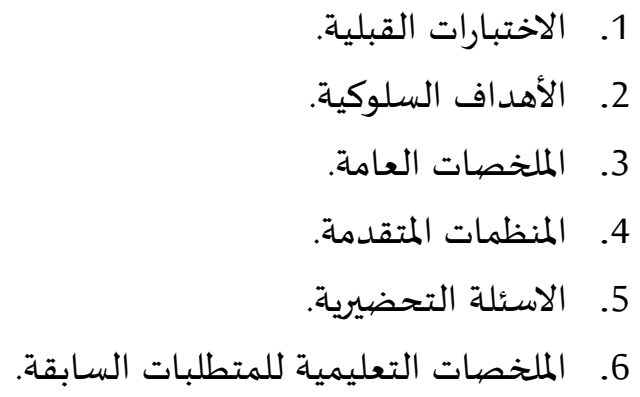

استراتيجية الملخصات التعليمية للمتطلبات السابقة: واحدة من استراتيجيات التدريس القبلية التي تعد قبل التدريس من قبل المعلم، ولهذه الاستراتيجية أهمية في تعليم الطلبة كما هو حال عملية التدريس نفسها، فهي تسهم في عملية التعليم من خلال ما تزود به المتعلمين من فكرة عامة أو ملخص مكتمل العناصر للمفاهيم والمعارف

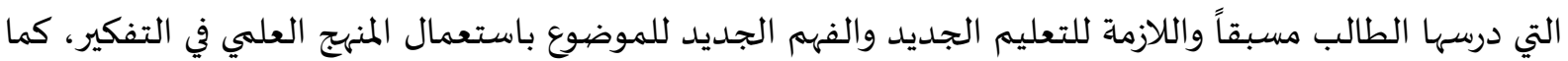

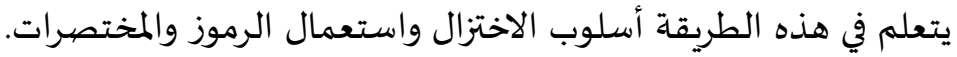
ويكمن نجاح هذه الاستراتيجية في طريقة إعدادها واهتمامها بالنقاط الرئيسية في المادة الدراسية التي

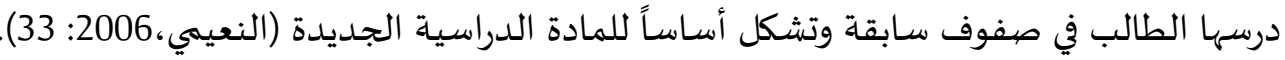

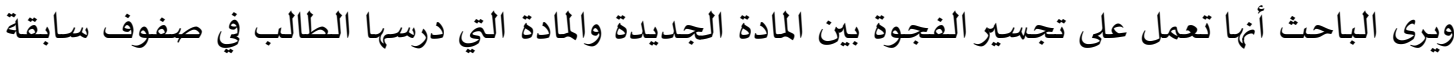
خصوصاً إذا كان هناك انقطاع في تدريس المفاهيم، فكلما كانت فترة الانقطاع طويلة أثر ذلك سلباً على اكتساب المادي الطلبة للمفاهيم المبنية عليها بالمستقبل. وبالتالي تدني التحصيل التهان الدراسي.

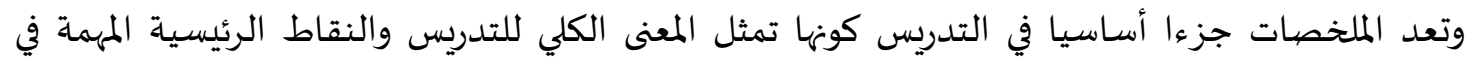

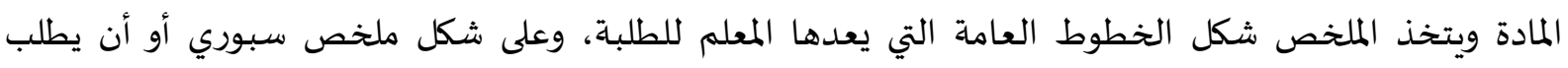

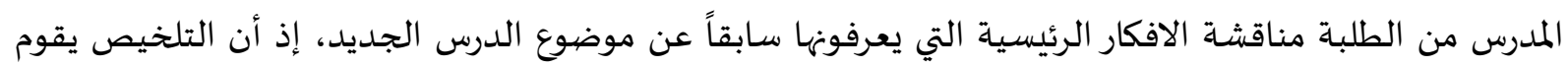

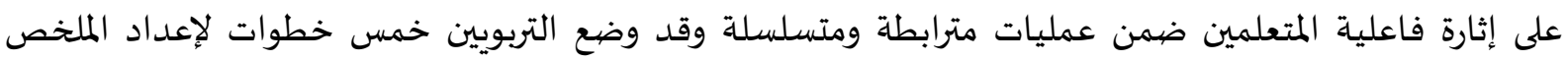

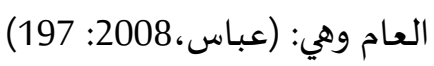
1. القاء نظرة عامة: Several

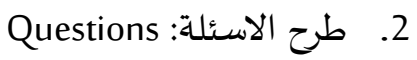
3ead

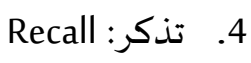
Review

ثانياً - الدراسـات السابقة: اطلع الباحث على ما تيسر له من دراسات ذات علاقة بموضيوع البحث من أجل الإفادة منها ومن اجراءات البحث والمعالجات العلمية فيها، وسيعرض الباحث هذه الدراسات وفقاً للتسلسل الزمني من الأقدم إلى الأحدث:

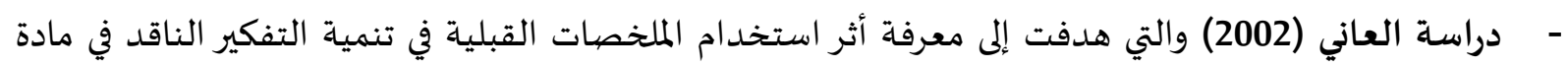

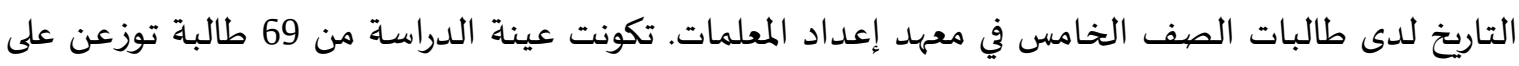

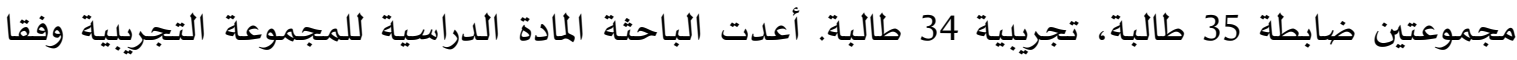

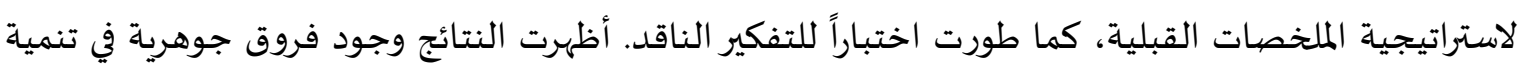
التفكير الناقد بين متوسط درجات المجموعة الضابطة والمجموعة التجريبية ولصالح المجموعة التجريبية. 
دراسة القرة وغوني (2004) حيث استهدفت تقصي أثر استخدام الملخصات العامة في تحصيل طلاب الصف

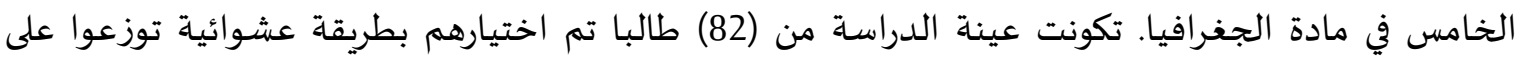

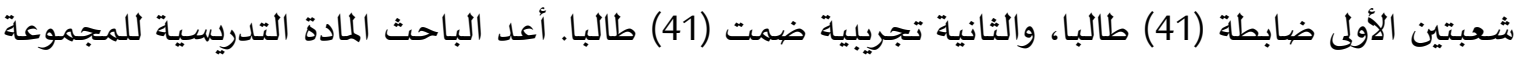

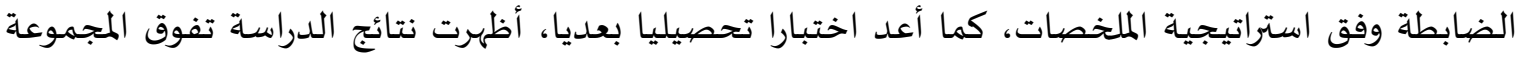

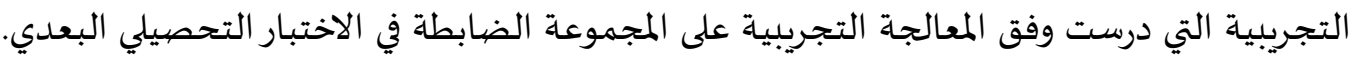

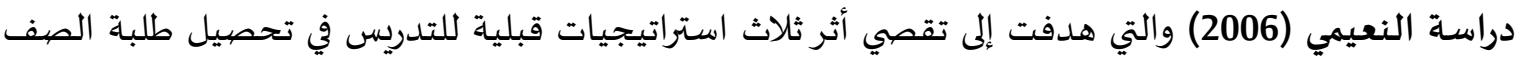

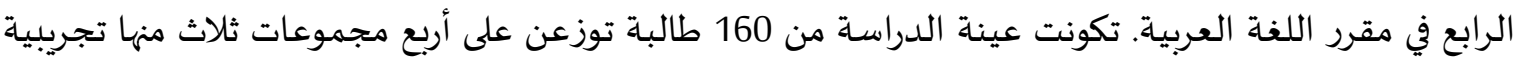

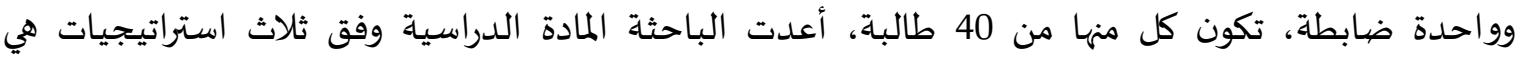

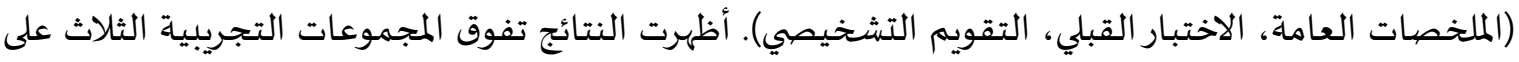

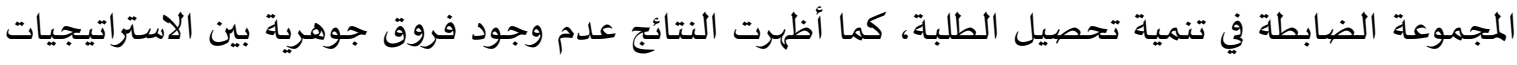

الثلاث في تنمية التحصيل.

دراسة عباس (2008) والتي هدفت إلى تقصي أثر استراتيجية الملخصات القبلية على التحصيل والاستبقاء لدى تلى

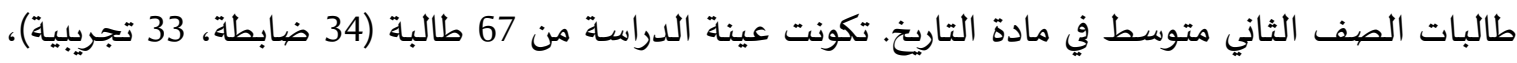

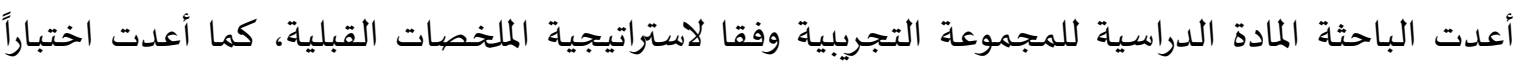

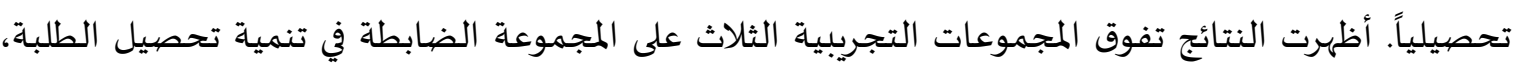
كما أظهرت النتائج وجود فروق جوهرية في استبقاء المعلومات (الاحتفاظ بالتحصيل) بين استراتيجية الملخصيات القبلية والطريقة الاعتيادية لصالح استراتيجية الملخصيات القبلية. كما هدفت دراسة أبو عواد وعياش (2012) إلى استقصاء أثر استراتيجية التدريس التبادلي للمتطلبات السابقة والمادة الدراسية الجديدة في تحصيل طالبات الصف التاسع الأساسي في مادة الأحياء (وحدة الضبط الضيط والتنظيم)

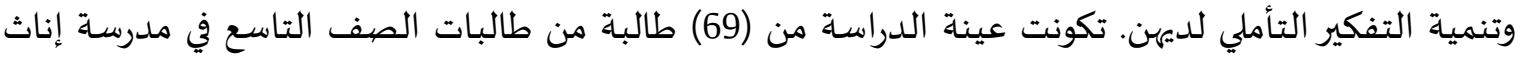

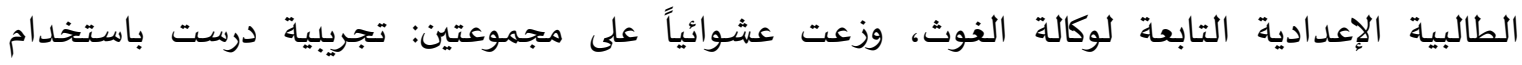

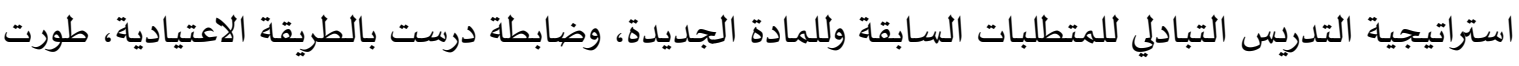

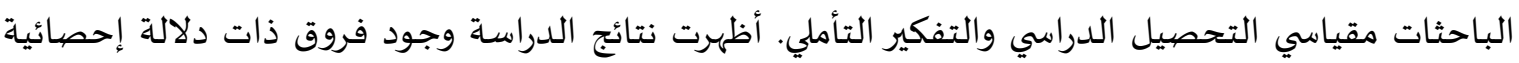

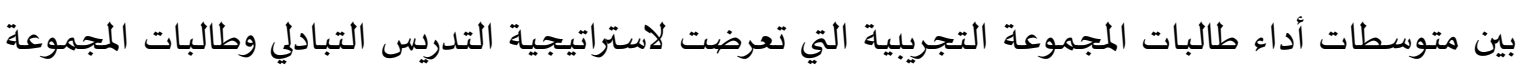

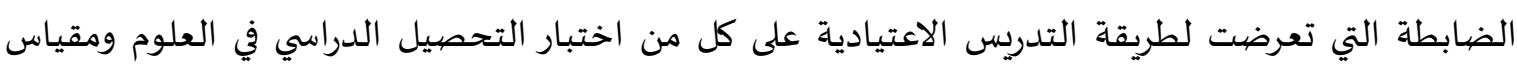
التفكير التأملي لصالح طالبات المجموعة التجريبية. دراسة (Bulut, 2017)، والتي هدفت هذه الدراسة فحص تأثير موقف الكتابة وكتابة معتقدات الكفاءة الذاتية على التحصيل في كتابة الملخصات لطلاب الصف الرابع الابتدائي باستخدام نمذجة المدابة المعادلة الهيكلية،

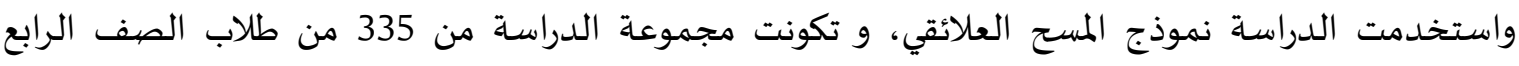
الابتدائي بطريقة العينة العشوائية البسيطة في جمع بيانات البحث، تم كتابة "مقياس كتابة الفعالية الذاتية ،

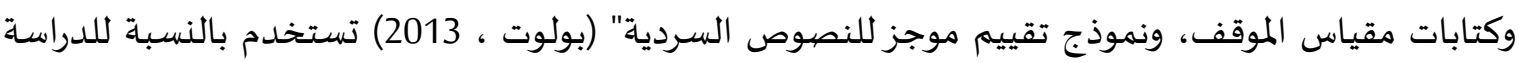

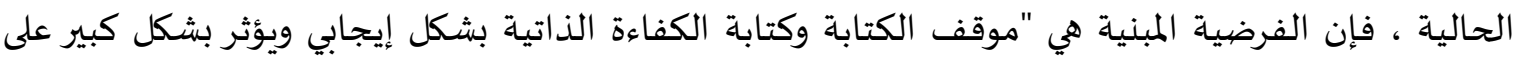

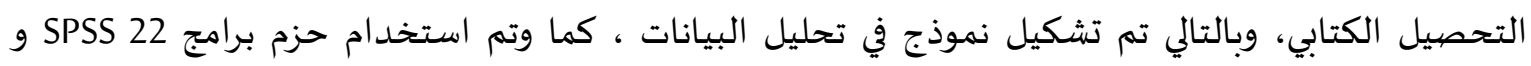
AMOS 22.0 وقد توصلت للدراسة، لنتيجة أن موقف الكتابة وكتابة معتقدات الكفاءة الذاتية يرتبطان ارتباطًا 
وثيقًا ببعضهما البعض وموقف الكتابة وكتابة معتقدات الكفاءة الذاتية بشكل مباشر ويؤثران بشكل كبير على كتابة الملخص. دراسة (Wilkinson 2012)، والتي هدفت هذه الدراسة إلى تحديد ما إذا كان تدريس استراتيجيات تدوين

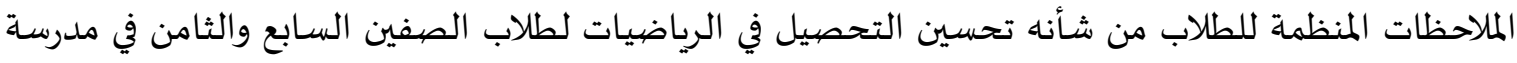

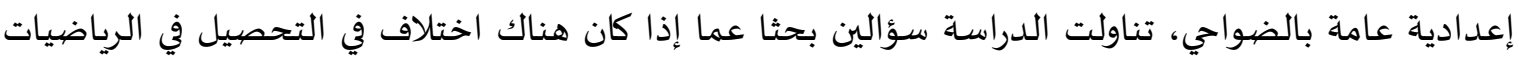

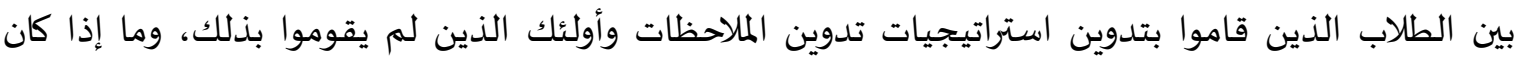

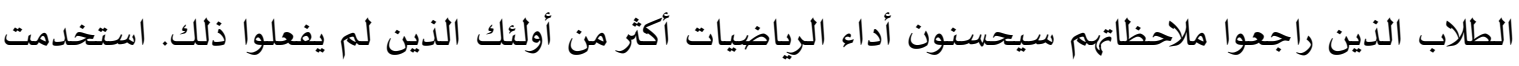

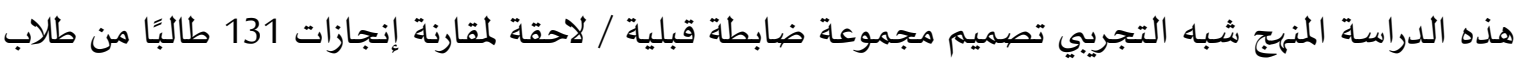

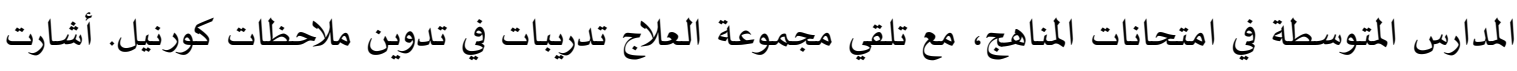
البيانات السابقة إلى عدم وجود فروق في التحصيل بين المجموعات قبل التدخل. أشار اختباران t إضافيان

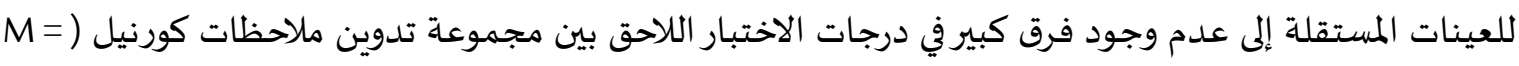

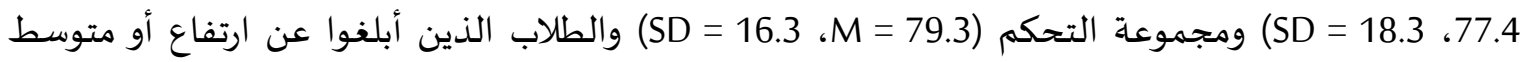
سجلت مستويات مراجعة الملاحظات درجات أعلى بشكل ملحوظ في الاختبارات اللاحقة من الطلاب الذين أبلغوا

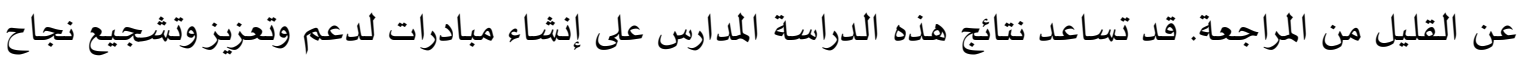
الطلاب ذوي التحصيل المنخفض في الرياضيات، وبالتالي زيادة احتمالية التغيير الاجتماعي الإيجابي.

التعليق على الدراسـات السابقة:

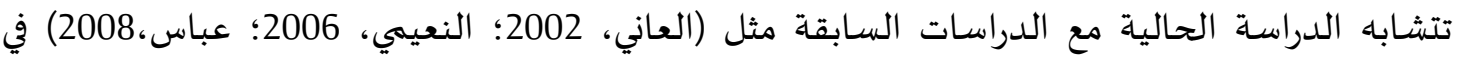

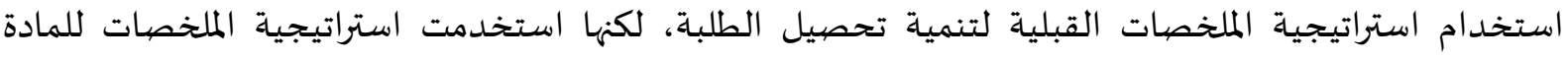

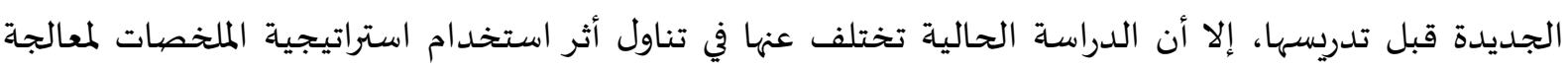

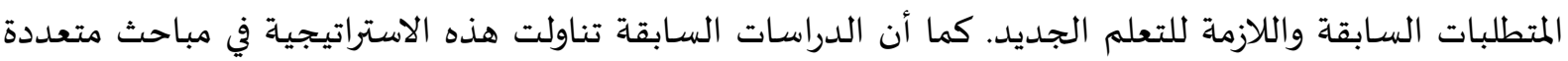
كالجغرافيا، والتارتخ، واللغة العربية، إلا أن الدراسة الحالية تتناول استخدانهات المها في مادة الأحياء.

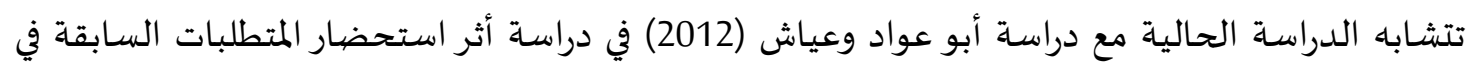

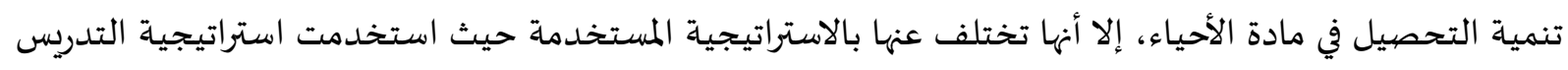

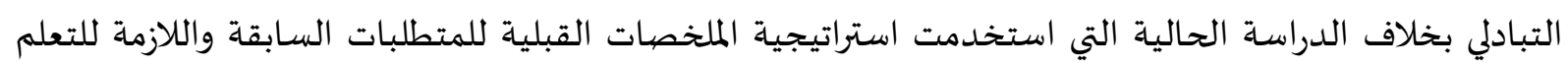
الجديد.

اتفقت الدراسة الحالية مع الدراسات السابقة من ناحية الهدف من الدراسة، حيث هدفت دراسة (Bulut,2017)

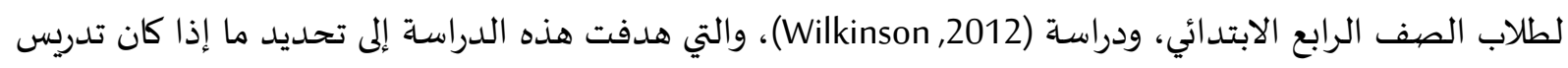

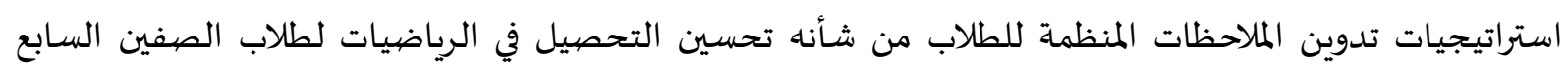

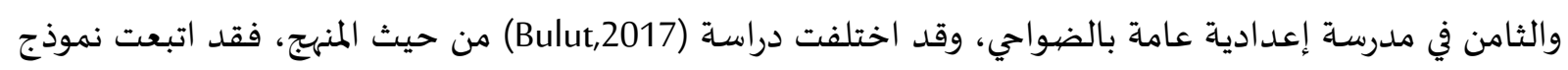

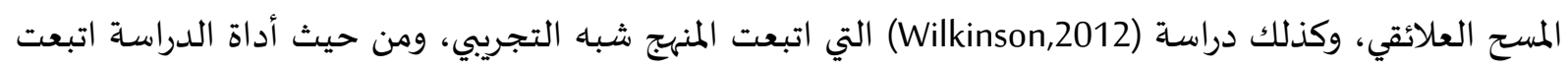
ودراسة (Bulut,2017) اتبعت مقياس كتابة الفعالية الذاتية. 


$$
\text { منهج البحث: }
$$

وفقاً لطبيعة هذا البحث، فإن الباحث استخدم كلاً من المنهج الوصفي في تصميم الملخصات التعليمية

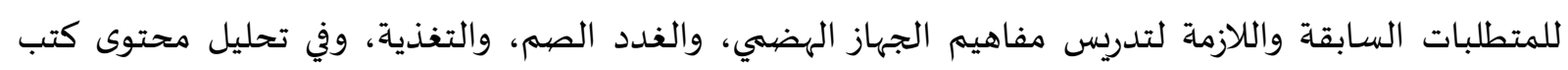

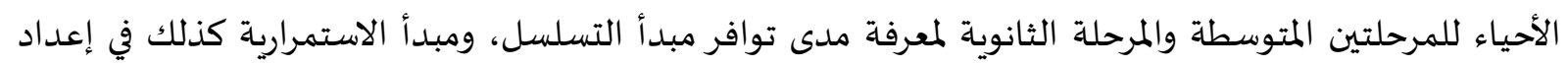

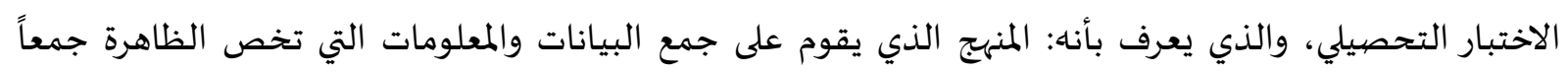

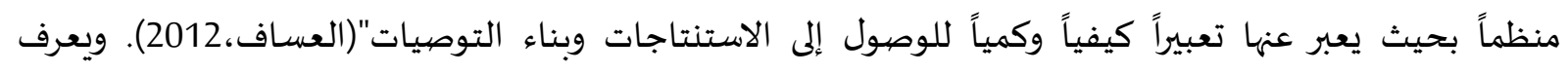

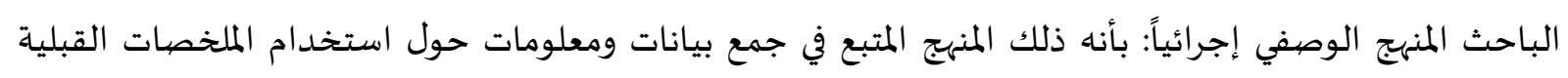

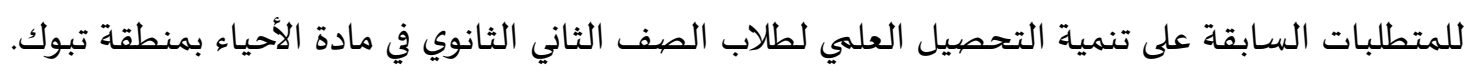

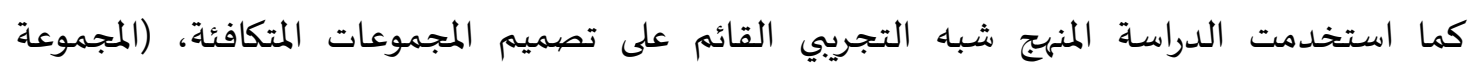

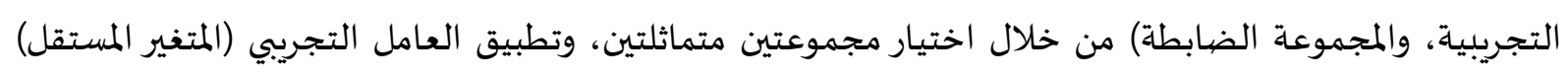

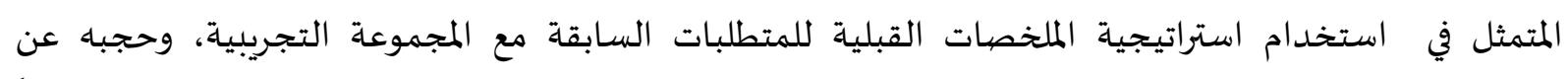

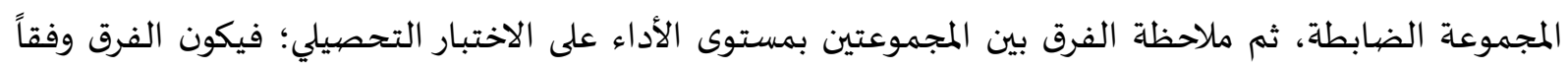

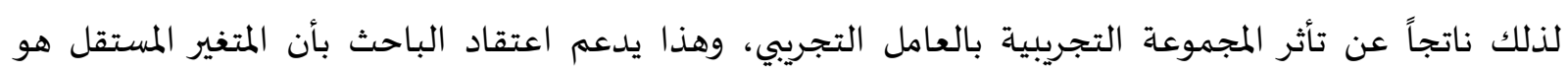

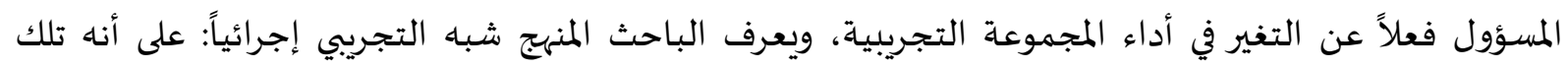

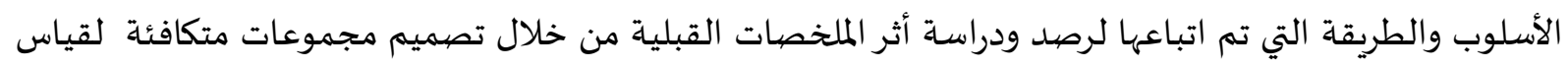

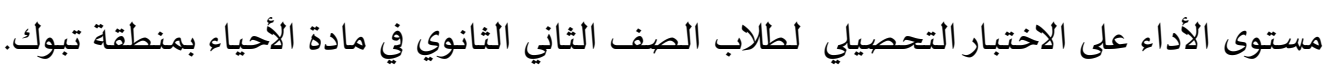
وعليه اعتمد الباحث التصميم الموضح بالشكل رقم (1) لتحقيق هدف الدراسة وهو على النحو التالي:

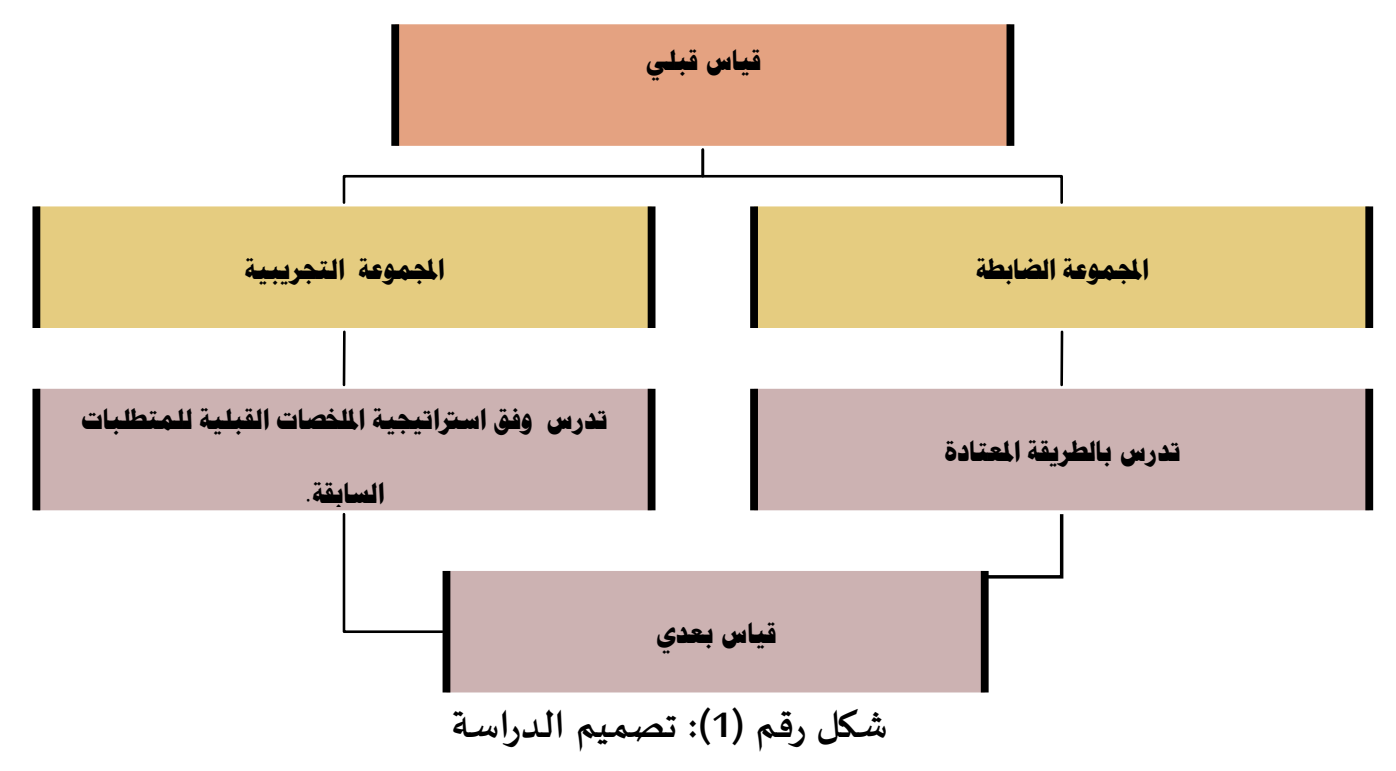

مجتمع البحث:

يتكون مجتمع البحث الحالي من جميع طلبة الصف الثاني ثانوي في منطقة تبوك للعام الدراسي (1435/ 1436هـ) والبالغ عددهم (3756) طالباً. 
تم اختيار مدرسة ثانوية أسامة بن زيد ومدرسة ثانوية الملك فهد من مدارس مدينة تبوك بطريقة قصدية

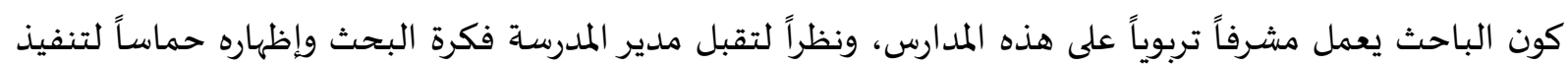

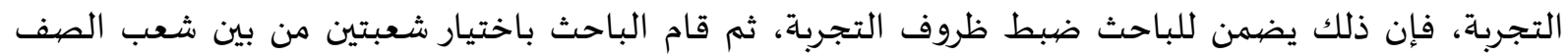

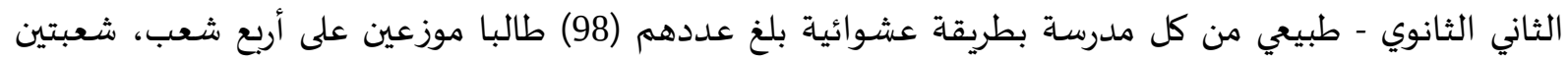

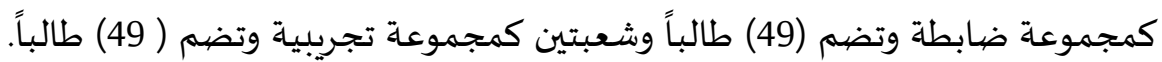

$$
\text { أدوات البحث: }
$$

- المادة التجريبية وفق استراتيجية الملخصيات التعليمية القبلية للمتطلبات السابقة. وفيما يلي عرضا تفصيليا لذلك:

أولاً: الاختبار التحصيلي:

يهدف هذا الاختبار لقياس مستوى أداء الطلبة في الفصل السابع من مادة الأحياء ويضيم الدروس "الجهاز

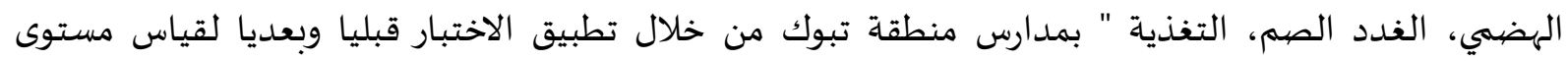
تحصيل الطلاب في عينة البحث، وقد قام الباحث بمجموعة من الخطوات قبل الوصول بالاختبار إلى صورته النهائية وهي على النحو التالي:

محتوى الاختبار: تم تحديد محتوى الاختبار من خلال تحديد الأهداف التعليمية المتضمنة في الدروس المختارة -

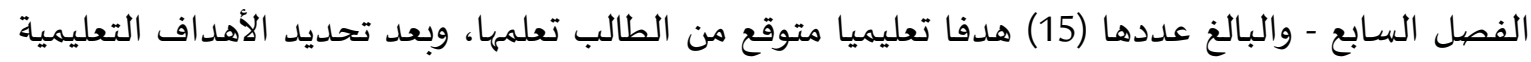

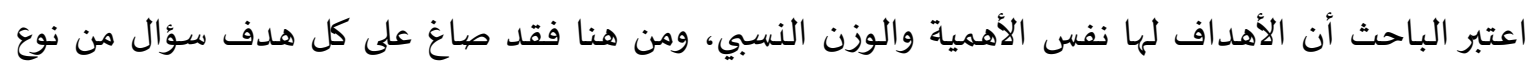
الاختيار من متعدد وبهذا يكون الاختبار من 15 فقرة من نوع الاختيار الاهنيار من متعدد.

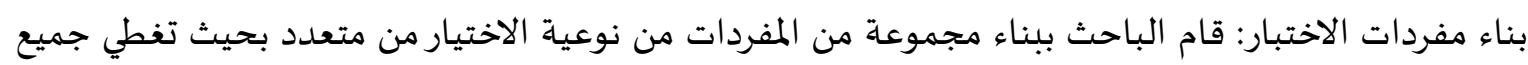
أهداف الوحدة المختارة وبهذا فقد احتوى الاختبار بصيورته الأولية 15 فقرة اختبارية. ضبط الاختبار: لضبط نوعية الاختبار والتحقق من الخصائص السيكومترية له (معامل الصعوبة، السهولة،

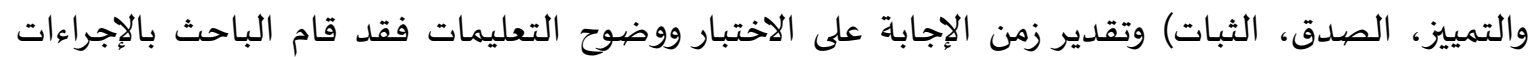

للتحقق من الصدق الظاهري (Face validity) للاختبار قام الباحث بعرض الاختبار على مجموعة من

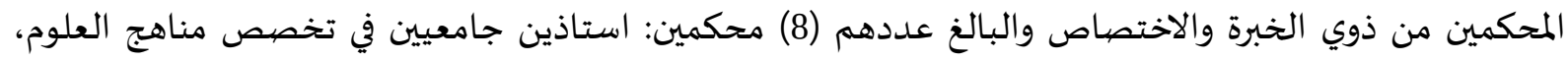
وأربعة مشرفين تربويين، ومعلمين، وبعد تعريفهم بموضوع البحث والهدف من إعداد الاختبار، طلب منهم الباحث

إبداء آرائهم وملاحظاتهم حول الأمور التالية:

- - مححة مفردات الاختبار من الناحية اللغوية. - قدرة مفردات الاختبار على قياس أهداف الوحدة. 
-

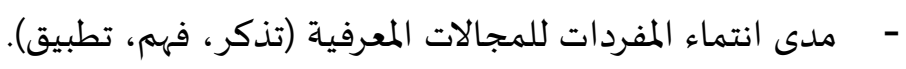
- اقتراح ما يرونه مناسبا من حذف أو تعديل.

وبناءً علياء تم قبول جميع فقرات الاختبار، والذي تكون في صوروتهاته النهائية من (15) فقرة.

التجبربة الاستطلاعية للاختبار:

للتحقق من مناسبة الاختبار للفئة المستهدفة بصورة ميدانية قام الباحث بتطبيقه على عينة عشوائية

مؤلفة من (25) طالبا من مجتمع الدراسـة ومن خارج عينتها، وقد تم استخراج الأمور التالية:

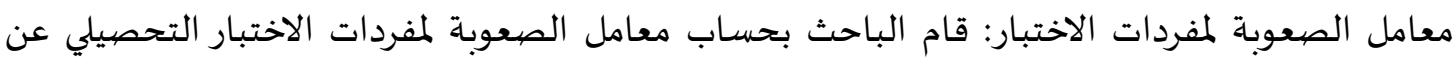

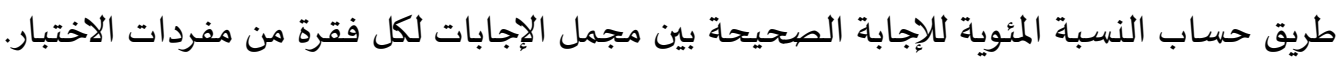
وتراوحت معاملات صعوبة مفردات الاختبار التحصيلي بين (0.21 - 0.83) مما يشير ذلك إلى أن الاختبار احتوى على تدرج واسع بمستويات صعوبة مفردات الاختبار ويعد ذلك مؤشرا على جودة مفردات الاختبار ومناسبتها

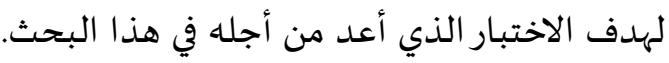

معاملات التمييز لمفردات الاختبار:

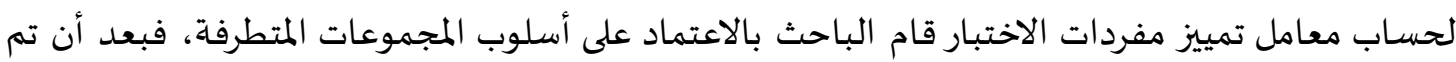

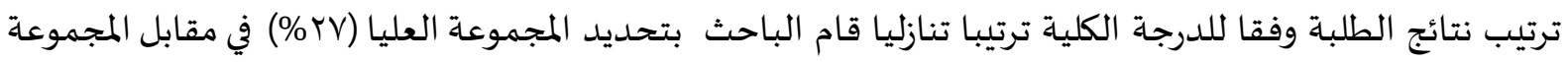
الدنيا (VY\%) وللوصول إلى مؤشر تمييز المفردات تم طرح الإجابات الصحيحة في المجموعة الدنيا من الإجابات

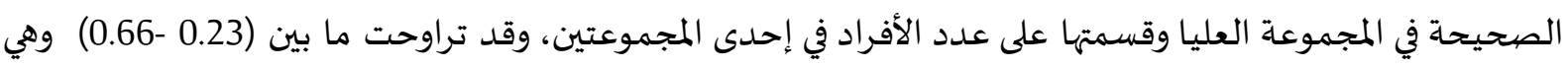

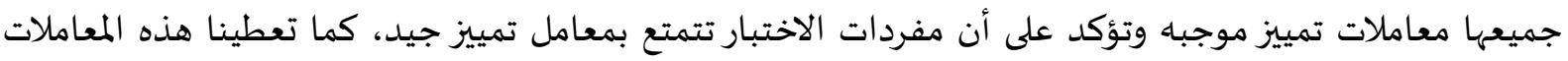

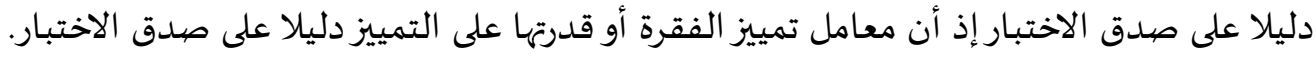

صدق الاتساق الداخلي (Internal Consistency Validity): كما تم التحقق من صدق الاتساق الداخلي (Internal Consistency Validity) لمفردات الاختبار عن طريق

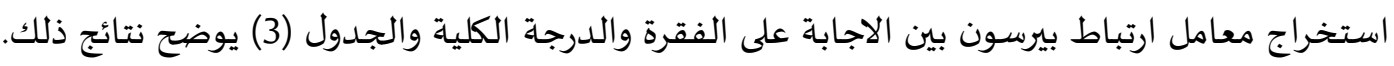

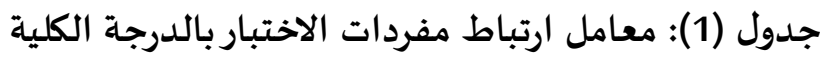

\begin{tabular}{|c|c|c|c|}
\hline معامل الارتباط & رقم الفقرة & معامل الارتباط & رقم الفقرة \\
\hline$* * 0.71$ & 9 & $* * 0.56$ & 1 \\
\hline$* * 0.55$ & 10 & $* 0.28$ & 2 \\
\hline$* * 0.32$ & 11 & $* * 0.60$ & 3 \\
\hline$* * 0.36$ & 12 & $* * 0.63$ & 4 \\
\hline$* * 0.40$ & 13 & $* * 0.51$ & 5 \\
\hline$* * 0.55$ & 14 & $* 0.29$ & 6 \\
\hline \multirow[t]{2}{*}{$* * 0.60$} & 15 & $* * 0.40$ & 7 \\
\hline & & $* * 0.41$ & 8 \\
\hline
\end{tabular}

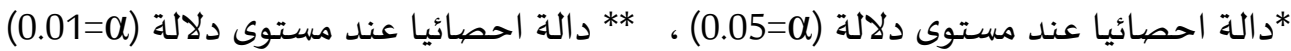


يظهر الجدول السابق بأن جميع معاملات الارتباط دالة احصائيا مما يدل على قوة الاتساق الداخلي

للتحقق من ثبات الاختبار قام الباحث باستخدام طريقة تطبيق وإعادة تطبيق الاختبار (Test-Retest) من

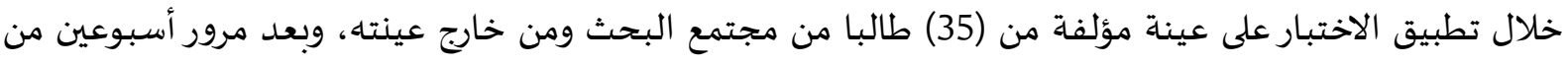

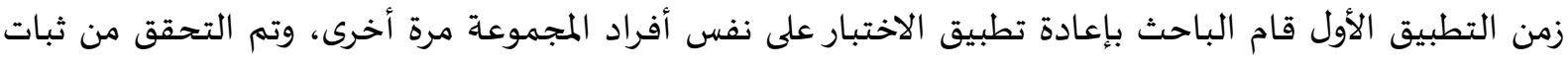
الأداة من خلال استخراج معامل ارتباط بيرسون بين مرتي التطبيق، حيث بلغت قيمته (0.89) وتعتبر مثل هذه القها القيمة مقبولة لأغراض الدراسة الحالية.

تعليمات الاختبار: تم وضع مجموعاة من التعليمات للطلاب بهدف توضيح الغرض من الاختبار وطريقة

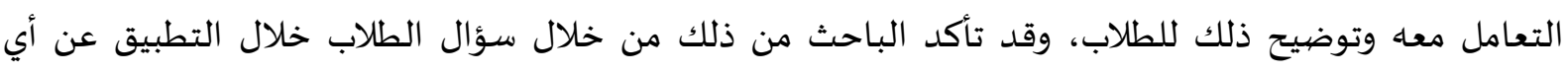

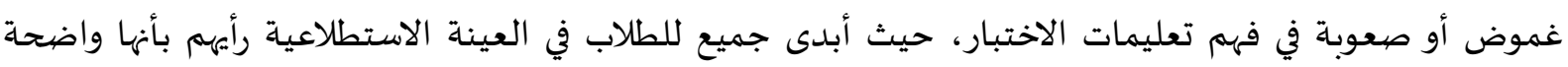

تقدير درجات الاختبار: تم تحديد درجة واحدة لكل إجابة صحيحة لكل مفردة من مفردات الاختبار وبذلك

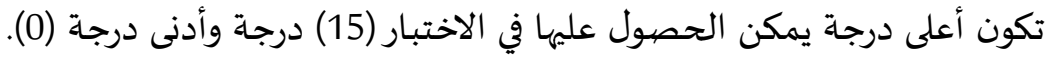

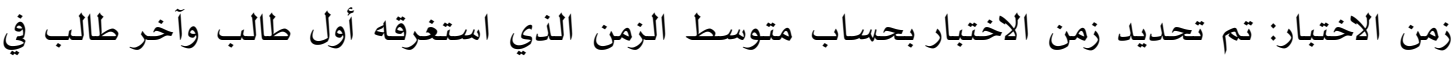

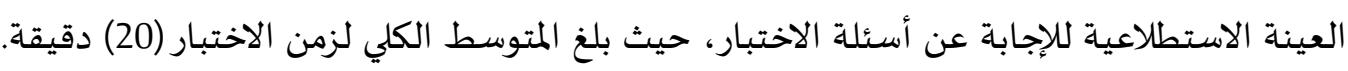

ثانياً: المادة التجريبية وفق استراتيجية الملمخصات التعليمية القبلية للمتطلبات السابقة:

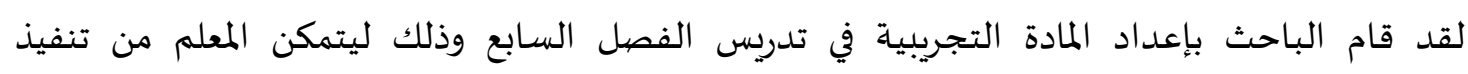
الاستراتيجية على أكمل وجها.

وقبل البدء بالتجربة تم التأكد من تكافؤ المجموعتين التجريبية والضابطة، حيث تم ذلك من خلال احتساب المتوسطات الحسابية والانحرافات المعيارية واختبار (ت) للعينات المستقلة لاستجابات أفراد عينة الدراسة

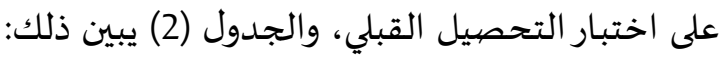

الجدول (2): المتوسطات الحسابية والانحرافات المعيارية واختبار (ت) للعينات المستقلة لاستجابات أفراد عينة الدراسـة على اختبار التحصيل القبلي

\begin{tabular}{|c|c|c|c|c|c|c|}
\hline الدلالة & قيمة & الانحراف المعياري & المتوسط & 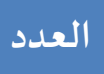 & المجموعة & المتغير التابع \\
\hline \multirow[t]{2}{*}{.260} & 1.132 & 4.71627 & 14.92 & 49 & ضابطة & اختبار التحصيل \\
\hline & & 4.37778 & 15.96 & 49 & تجريبية & القبلي \\
\hline
\end{tabular}

يتبين من الجدول (2) أن متوسط أداء المجموعة الضابطة على اختبار التحصيل القبلي بلغ (14.92)

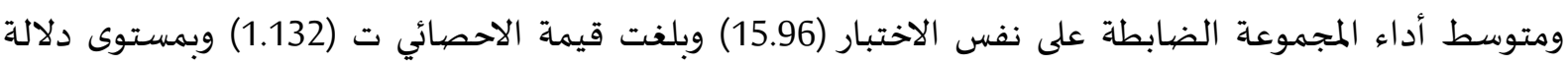

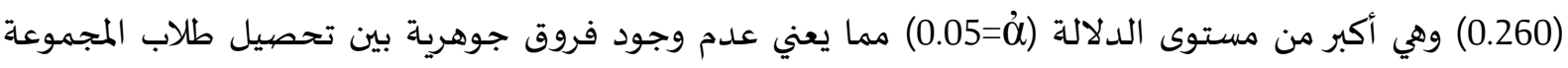

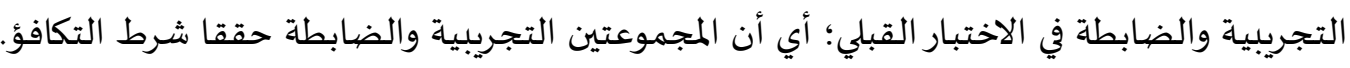


الأسـاليب الإحصيائية المستخدمة:

بعد استكمال جمع البيانات والمعلومات للإجابة عن أسئلة البحث، تم تحليل النتائج عن طريق استخدام

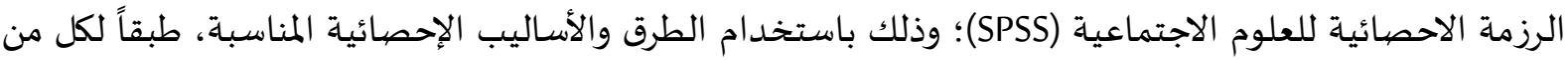
طبيعة المتغيرات وطبيعة توزيع عينة البحث وهي كالتالي:

معامل ارتباط بيرسون لحساب معامل ثبات الاختبارولحساب صددق الاتساق الداخلي لمفردات الاختبار. اختبار "ت" للعينات المستقلة (independent Sample T. Test) لمقارنة متوسطي المجموعتين (التجريبية، الضابطة) في التطبيق البعدي. مربع إيتا "ر2" لحساب حجم الأثر؛ لتعرف فعالية التدريس باستخدام الملخصات التعليمية القبلية للمتطلبات السابقة في تنمية تحصيل الطلاب في مادة الأحياء.

4. - نتائج الدراسـة ومناقشتها.

النتائج المتعلقة بالسؤال الاول: "ما مدى تحقيق مبدأ التسلسل ومبدأ الاستمرارية في عرض مفاهيم

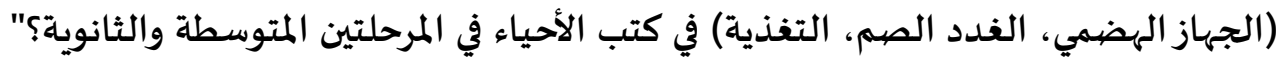

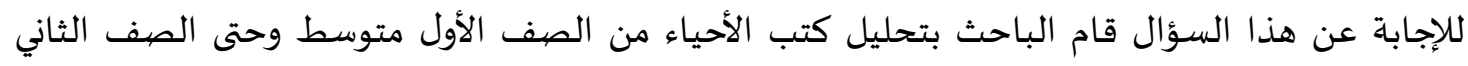

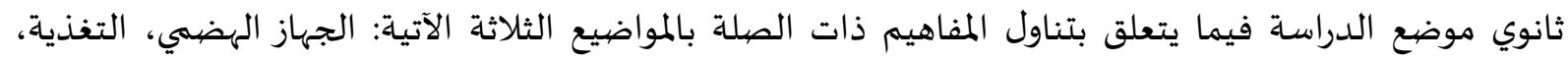
الغدد الصه، والجدول رقم (3) يبين هذه النتائج: الجدول (3): مدد الانقطاع الزمني بين موضوعات مواد الأحياء بالمرحلة الثانوية وبين سابقتها بالمراحل الدراسية السابقة في التكامل الرأسي لمناهج العلوم (الأحياء).

\begin{tabular}{|c|c|c|c|c|c|c|c|c|c|c|}
\hline بالفانقطاع الدرل & الدراسي & المرحلة & السابق & عنوان الدرس & $\overline{\overline{3}}$ & 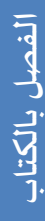 & $\bar{g}$ & $\bar{g}$ & $\overline{\bar{y}}$ & $\hat{\imath}$ \\
\hline- & - & - & - & مدخل إلى علم الأحياء & 1 & \multirow{2}{*}{1} & \multirow{10}{*}{ गু } & \multirow{14}{*}{ 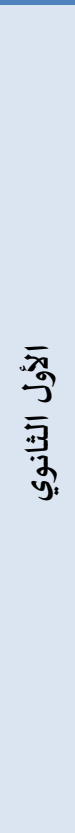 } & \multirow{14}{*}{ 诵 } & 1 \\
\hline 1 & 1 & المتوسطة & 3 & طبيعة العلم وطرائقه & 2 & & & & & 2 \\
\hline 9 & 1 & الابتدائية & 5 & تاريخ التصنيف & 1 & \multirow{2}{*}{2} & & & & 3 \\
\hline 9 & 1 & الابتدائية & 5 & التصنيف الحديث & 2 & & & & & 4 \\
\hline 7 & 1 & الابتدائية & 6 & البكتيريا & 1 & \multirow{2}{*}{3} & & & & 5 \\
\hline 9 & 1 & الابتدائية & 5 & الفيروسات والبريونات & 2 & & & & & 6 \\
\hline 7 & 1 & الابتدائية & 6 & مدخل إلى الطلائعيات & 1 & \multirow{2}{*}{4} & & & & 7 \\
\hline 7 & 1 & الابتدائية & 6 & تنوع الطلائعيات & 2 & & & & & 8 \\
\hline 7 & 1 & الابتدائية & 6 & مدخل إلى الفطريات & 1 & \multirow{2}{*}{5} & & & & 9 \\
\hline 7 & 1 & الابتدائية & 6 & تنوع الفطريات وبيئهها & 2 & & & & & 10 \\
\hline 4 & 2 & المتوسطة & 1 & خصائص الحيوانات & 1 & \multirow{3}{*}{6} & \multirow{4}{*}{$\frac{\sqrt{3}}{3}$} & & & 11 \\
\hline 4 & 2 & المتوسطة & 1 & مستويات بناء جسم الإنسان & 2 & & & & & 12 \\
\hline 4 & 2 & المتوسطة & 1 & الإسفنجيات واللاسعات & 3 & & & & & 13 \\
\hline 4 & 2 & المتوسطة & 1 & الديدان المفلطحة & 1 & 7 & & & & 14 \\
\hline
\end{tabular}




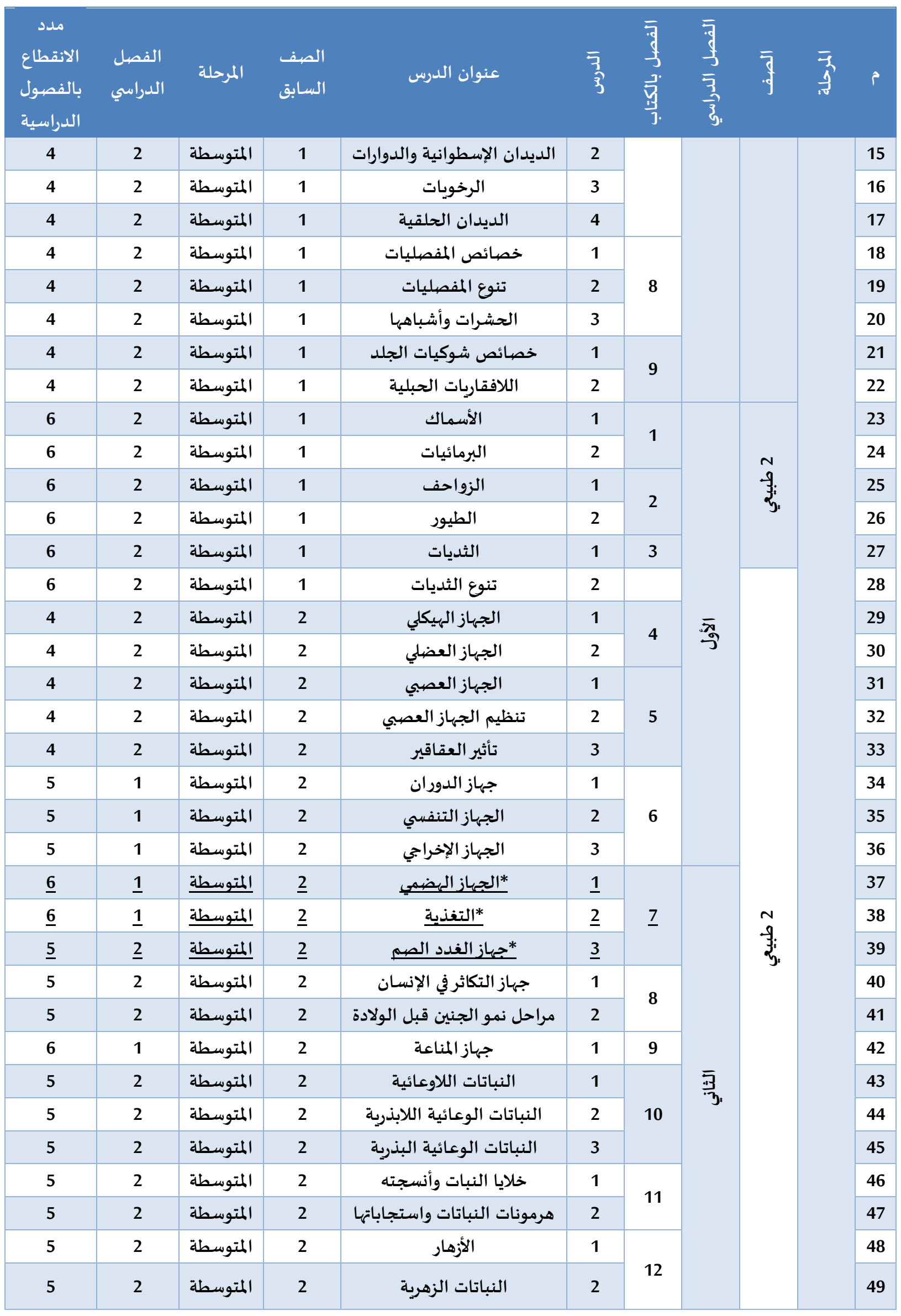




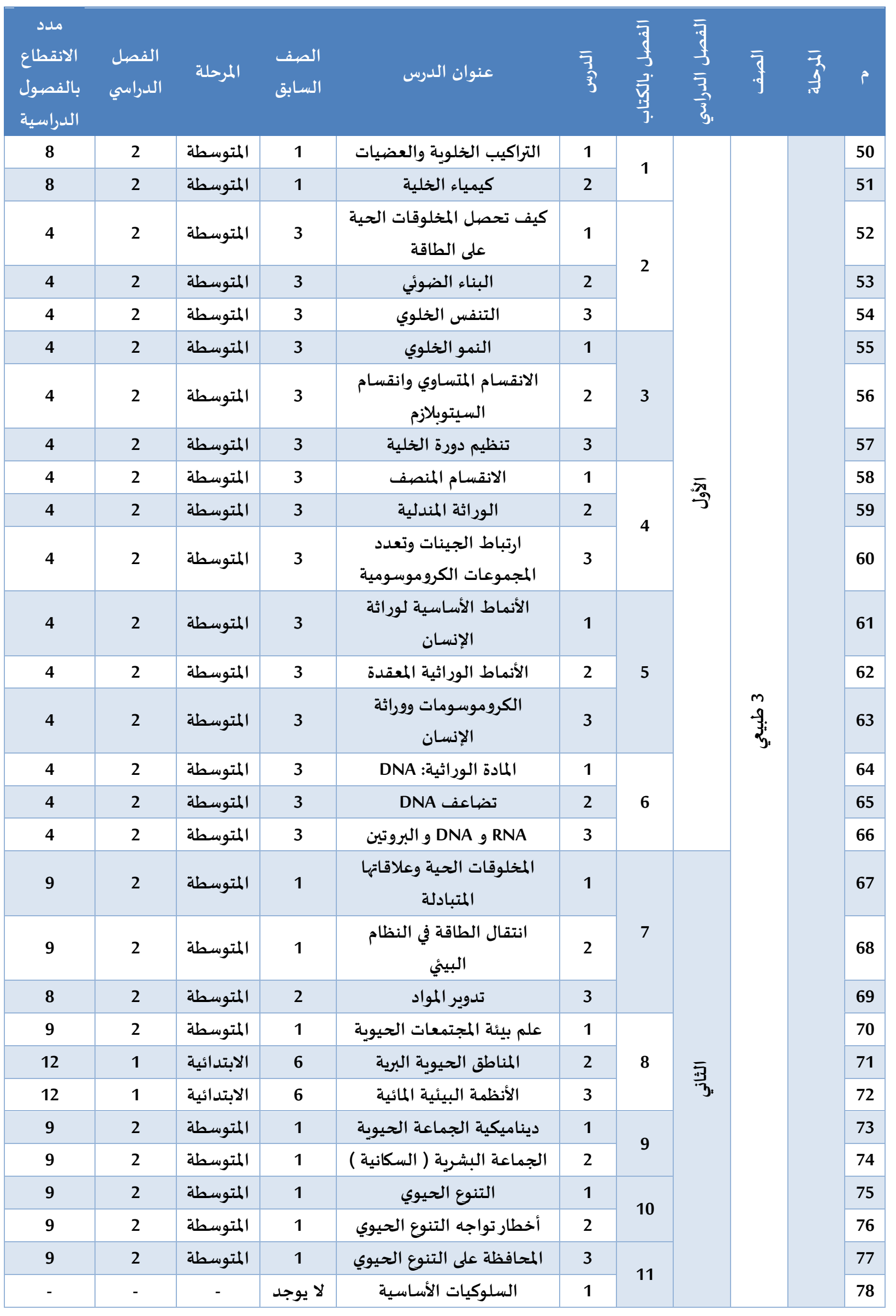




\begin{tabular}{|c|c|c|c|c|c|c|c|c|c|c|}
\hline الالنقاع & الدراسي & المرحلة & السابق & عنوان الدرس & $\overline{3}$ & $\begin{array}{l}\bar{y} \\
-3 \\
\overline{3} \\
\frac{3}{3} .\end{array}$ & $\begin{array}{l}\bar{y} \\
\hat{5} \\
\overline{3} \\
\overrightarrow{3}\end{array}$ & $\overline{\mathrm{j}}$ & $\bar{\jmath}$ & e \\
\hline- & - & - & لا يوجد & السلوكيات البيئية & 2 & & & & & 79 \\
\hline
\end{tabular}

يبين الجدول (3) تحليل لكتل العلوم (الأحياء) عبر المراحل الدراسية والذي يشير إلى:

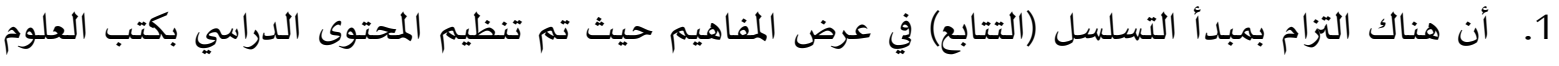

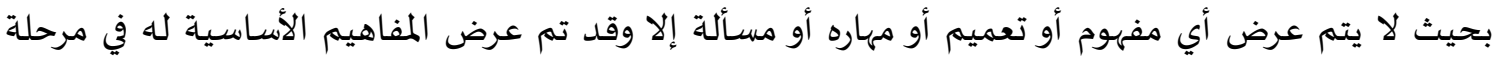
2. أن هناك عدم التزام بمبدأ الاستمرارية في المفاهيم المتعلقة بالجهاز الهضمي والغدد الصهم والتغذية والتي تم التم التها

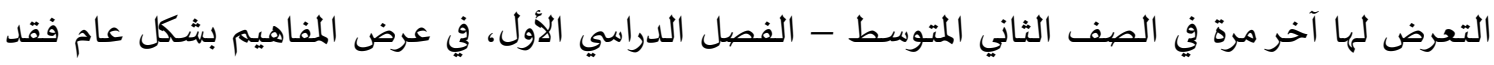
تراوحت فترات الانقطاع في تدريس المفاهيم بين فصل واحد إلى 12 فصل دراسي، فمثلا مفاهيم (المناطق المانق

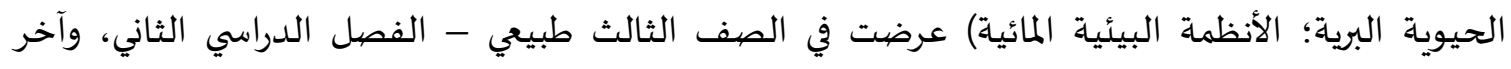

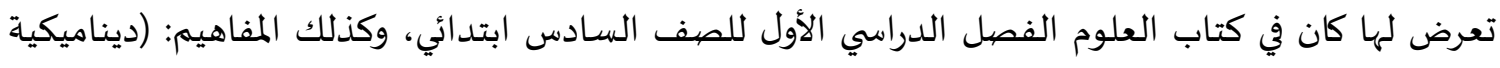

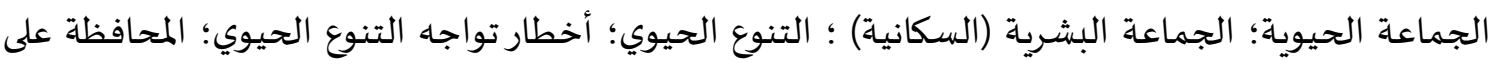

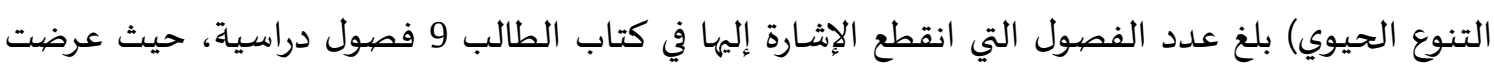

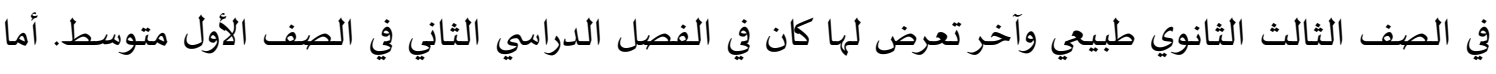

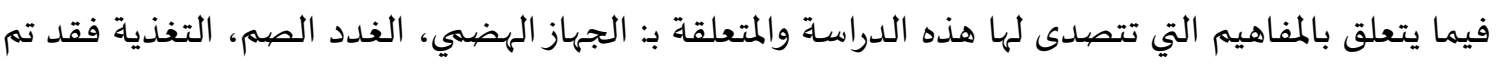

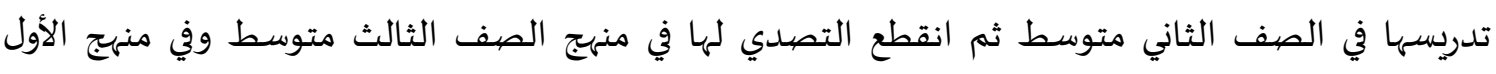

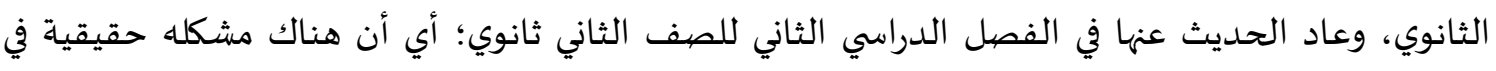
تنظيم محتوى كتب العلوم فيمكننا أن نعمم أنها لم تلتزم بمبدأ الاستمرارية.

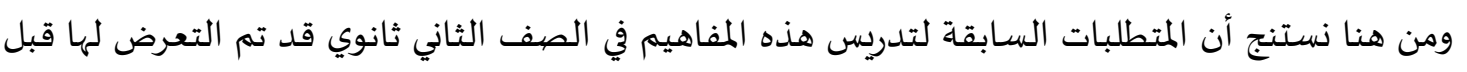
عامين ونصف، مما يجعل مهمة تذكرها صعبة على التلاميذ؛ ومن هنا يعتقد الباحث أهها قد تشكل عائقاً حقيقيا

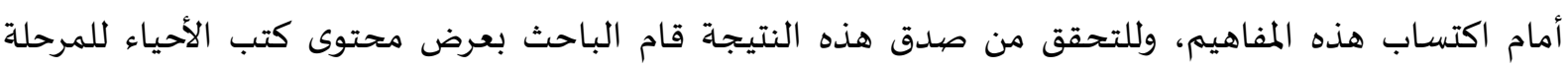

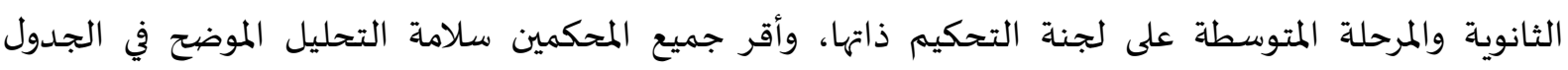
السابق، مما يطمئن الباحث على صحة هذه النتيجة. وهذه النتيجة لم تتوافر في الدراسات السابقة حيث أهملت الدراسات السابقة التي تيسر للباحث الاطلاع عليها عملية تقصي التسلسل والاستمرارية في عرض مفاهيم الأحياء بين المرحلة المتوسطة والثانية الثماتية. النتائج المتعلقة بالسؤال الثاني: " ما أثر استخدام استراتيجية الملخصيات القبلية للمتطلبات السابقة على المئل

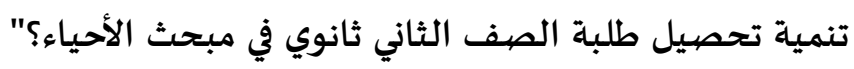
للإجابة عن هذا السؤال حسبت المتوسطات الحسابية والانحرافات المعيارية واختبار (ت) للعينات المستقلة

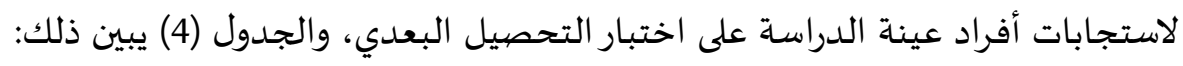


الجدول (4): المتوسطات الحسابية والانحرافات المعيارية ونتائج اختبار (ت) لاستجابات افراد الدراسة على الاختبار التحصيلي البعدي

\begin{tabular}{|c|c|c|c|c|c|c|}
\hline الدلالة الاحصيائية & $\begin{array}{c}\text { قيمة } \\
T\end{array}$ & الانحراف & المتوسط & العدد العد & المجموعة & المتخير التابع \\
\hline \multirow{2}{*}{.232} & \multirow{2}{*}{1.202} & 2.77363 & 6.8776 & 49 & ضابطة & اختبار التحصيل البعدي \\
\hline & & 2.93684 & 7.5714 & 49 & تجريبية & بعد الجهاز الهضي \\
\hline \multirow{2}{*}{.010} & \multirow{2}{*}{2.629} & 2.93828 & 8.6939 & 49 & ضابطة & اختبار التحصيل البعدي \\
\hline & & 2.82301 & 10.2245 & 49 & تجريبية & بعد التغذية \\
\hline \multirow{2}{*}{.000} & \multirow{2}{*}{5.309} & 3.71886 & 5.4082 & 49 & ضابطة & اختبار التحصيل البعدي \\
\hline & & 3.96391 & 9.5306 & 49 & تجريبية & بعد الغدد الصهم \\
\hline \multirow{2}{*}{.000} & \multirow{2}{*}{4.315} & 7.81422 & 20.9796 & 49 & ضابطة & اختبار التحصيل البعدي \\
\hline & & 6.70319 & 27.3265 & 49 & تجريبية & 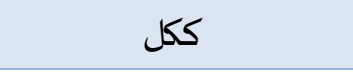 \\
\hline
\end{tabular}

يتبين من الجدول (4) ما يلي:

1. لا توجد فروق ذو دلالة احصائية عند المستوى (م = 0.05) بين متوسط أداء المجموعتين التجريبية والضابطة

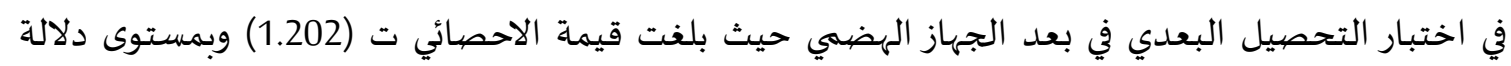

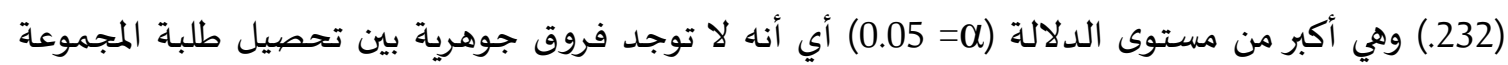
التجريبية والضابطة على بعد الجهاز الهضيمي.

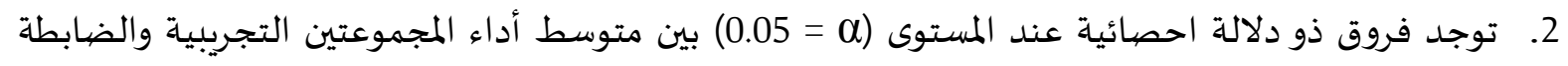
في اختبار التحصيل البعدي في بعد التغذية حيث بلغت قيمة الاحصائي ت (2.629) وبمستوى دلالة المانة (0.010)

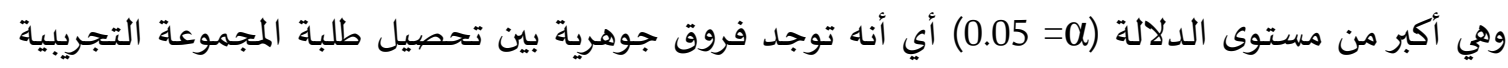

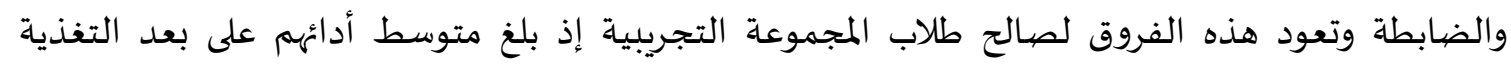
(10.2245) وهو أعلى من متوسط أداء طلاب المجموعة الضابطة على نفس البعد والبالغ (8.6939).

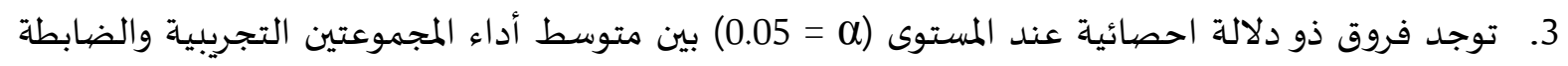

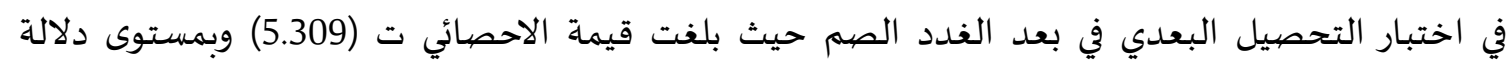

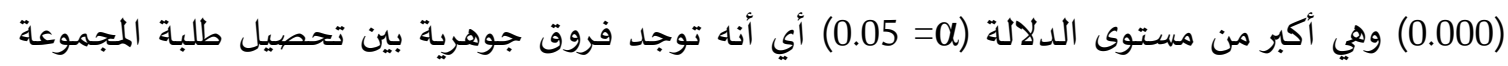

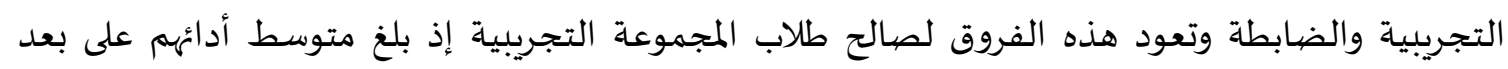

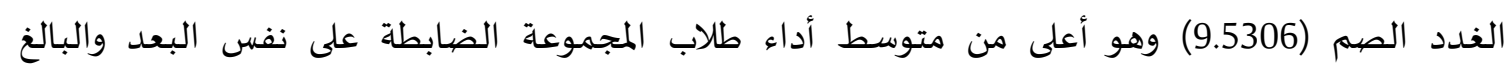

4. توجد فروق ذو دلالة احصائية عند المستوى (م = 0.05) بين متوسط أداء المجموعتين التجريبية والضابطة

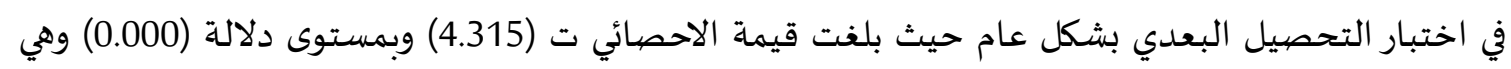

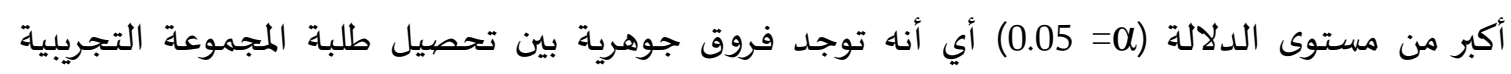

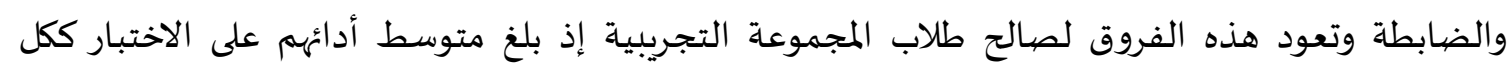
(27.3265) وهو أعلى من متوسط أداء طلاب المجموعة الضابطة والبالغ (20.9796). 
يفسر الباحث عدم وجود فروق ذو دلالة احصائية عند المستوى (م = 0.05) بين متوسط أداء المجموعتين

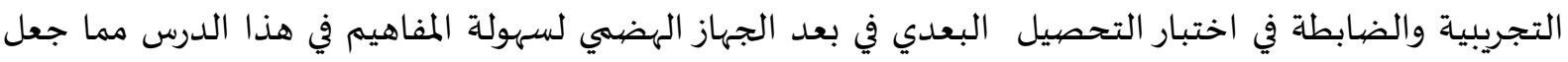

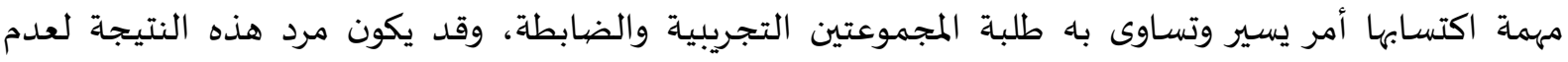

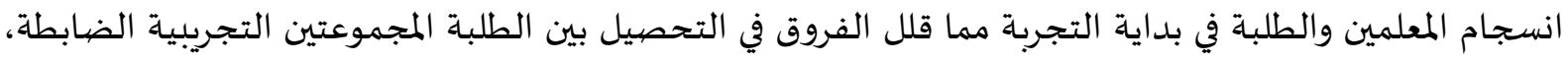
وسرعان ما تغير هذا الأمر فقد أظهرت نتائج الدراسة وجود فروق جوهرية بين تحصيل طلبة المجموعاة التجريبية

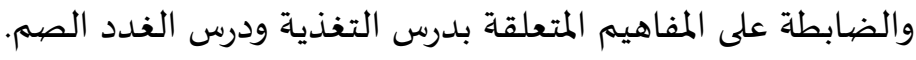

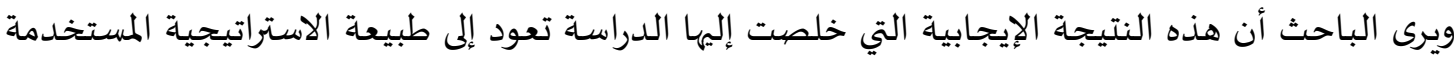

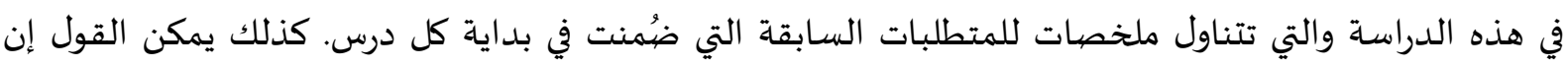

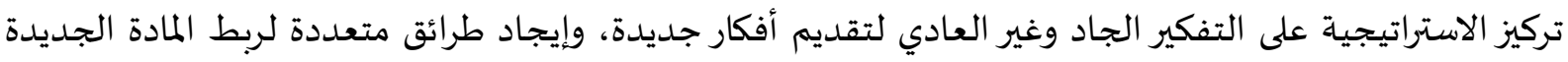

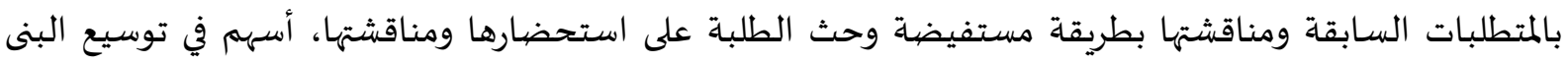

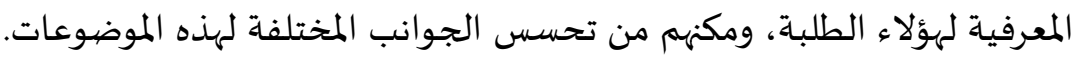

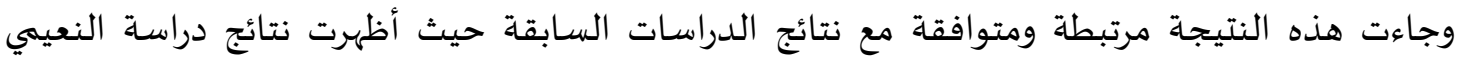

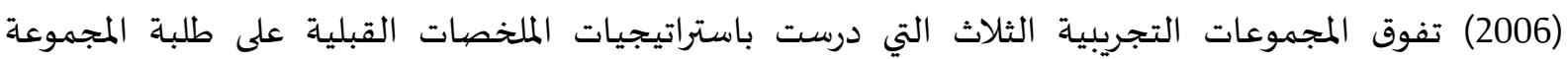
الضابطة التي درست بالطريقة التقليدية. وتتفق مع نتائج دراسة عباس (2008) التي أظهرت فاعلية استراتيجية الملخصيات القبلية على تحسين تحصيل الطلبة والاستبقاء بالتحصيل. كما تتفق مع نتائج دراسة أبو عواد وعايش (2012) التي أظهرت تفوق المجموعة التجريبية التي درست باستراتيجيات التدريس التبادلي للمتطلبات السابقة على طلبة المجموعة الضابطة التي درست بالطاتئ الطريقة التقليدية. ملخص نتائج الدراسة: 1. قدمت الدراسة استفادة لأثر استخدام الملخصات القبلية للمتطلبات السابقة على تنمية التحصيل العلمي لطلاب الصف الثاني الثانوي في مادة الأحياء بمنطقة تبوك، حيث تم تحليل محتوى كتب الأحياء للمرحلتين

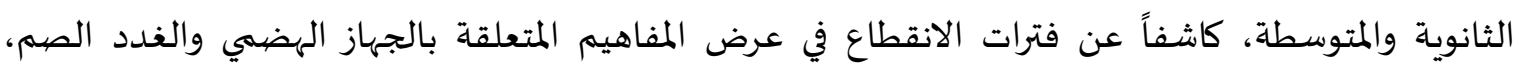

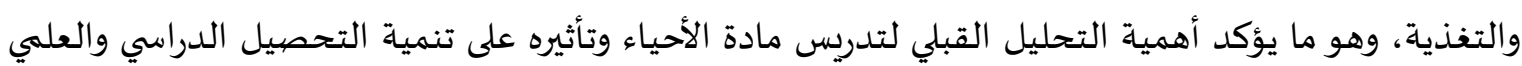
لدى الطلبة. 2. لقد أظهرت الدراسـة مدى تحقيق مبدأ التسلسل ومبدأ الاستمرارية في عرض مفاهيم (الجهاز الهضمي، الغدد

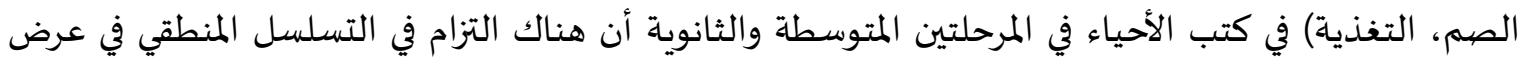
المفاهيم حيث تم تنظيم المحتوى الدراسي بكتب العلوم بحيث لا يتم عرض أي مفهوم أو تعميم أو مهاره أو الو الماء

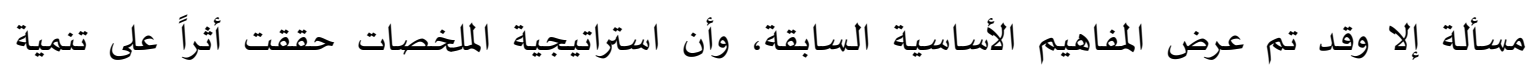
التحصيل الدراسي. 3. كما أظهرت الدراسة أثر استخدام استراتيجية الملخصات القبلية للمتطلبات السابقة على تنمية تحصيل طلبة

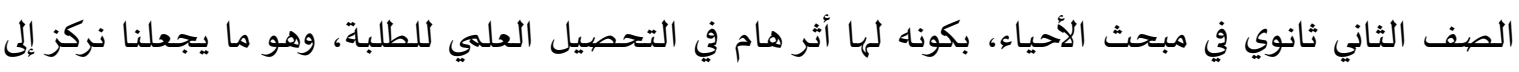

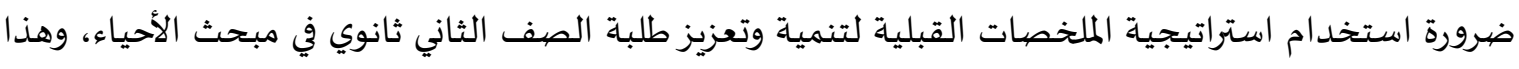

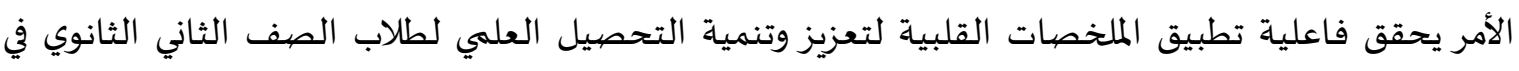
مادة الأحياء بمنطقة تبوك. 
1. دعوة القائمين على تطوير مناهج العلوم بشكل عام ومنهج الأحياء بشكل خاص إلى اتخاذ تصهميم المنهج الحلزوني في تصميم محتوى هذه المناهج والذي يجمع بين مبدئي التسلسل والاستمرارية في تنظيم محتوى المنهيج.

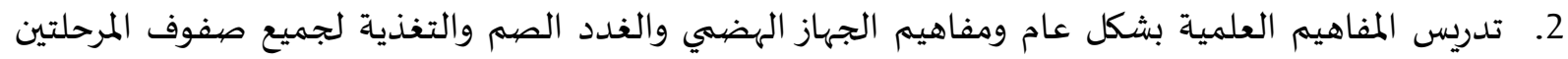

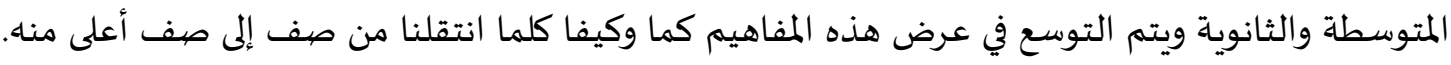

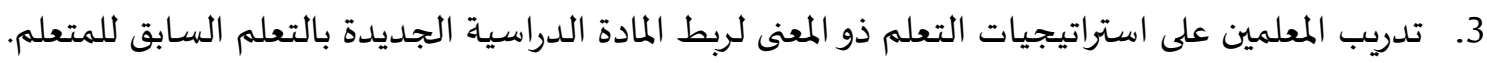
4. تضمين أدلة المعلمين تدريبات وتمارين لعلاج جميع أهداف التعلم السابق ليكون المتعلمون جاهزين للتعلم الجديد.

5. العمل على إيجاد دليل محوسب للمتطلبات السابقة يقدم مجموعاه عديدة ومتنوعة من التمارين المتعلقة بالمتطلبات السابقة وبمستويات متعددة لكي تتناسب مع الفروق الفردية للطلبة.

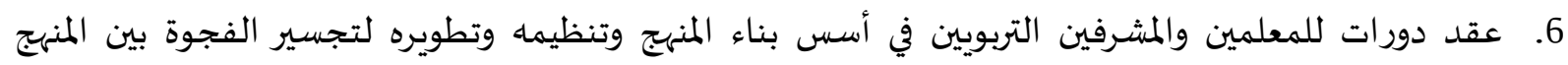
الرسمي ووسائل تنفيذه من كتب وأدلة تعليمياة.

قائمة المراجع. - أبو عواد، فريال محمد؛ وعياش، آمال نجاتى (2012). أثر استراتيجية التدريس التبادلي في تنمية التحصيل الدراسي والتفكير التأملي لدى طالبات الصفف التاسع الأساسي. مجلة جامعة الخليل للبحوث، 7 (2).

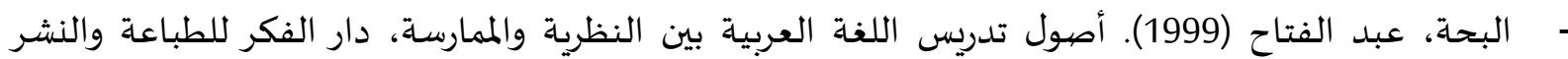

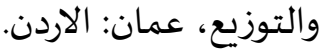

- - حميدة، امام وآخرون (2000). تدريس الدراسات الاجتماعية في التعليم العام، مكتبة زهراء الشرف، ط1، ج2.

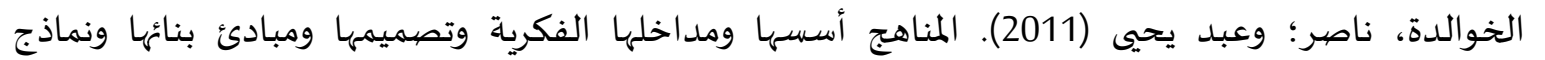
تطويرها. دارزمزم للنشر والتوزيع، عمان: الاردن.

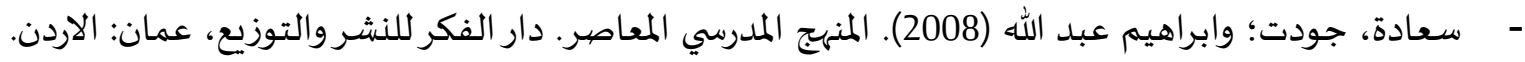
- الشولي، مريم (2013). مدى تمكن معلمات العلوم من مهارات تدريس المفاهيم في ضوء متطلبات علمبات المنهج المطور

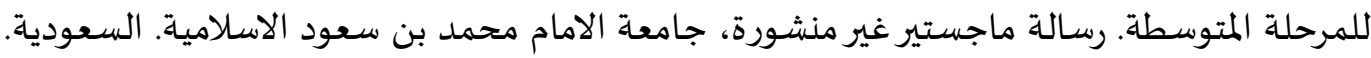

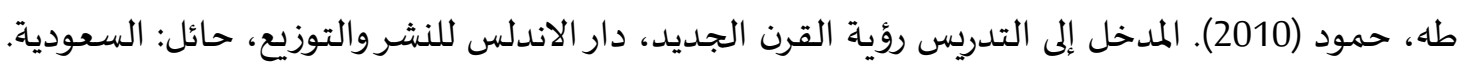

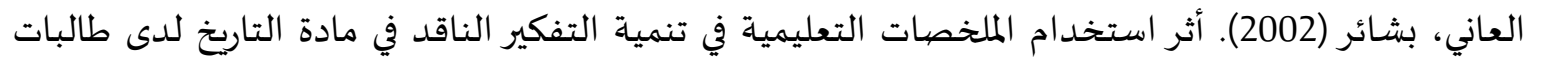

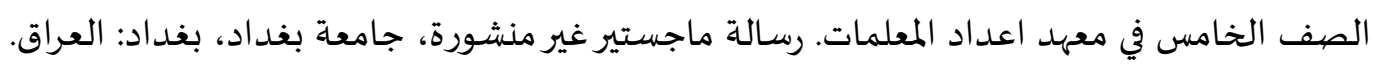

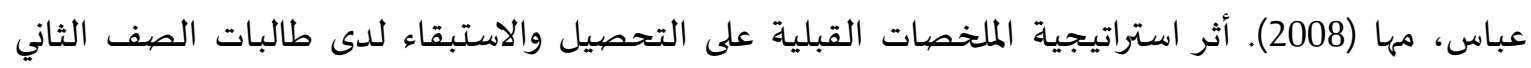

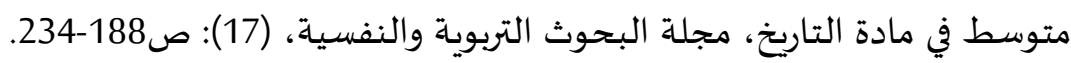

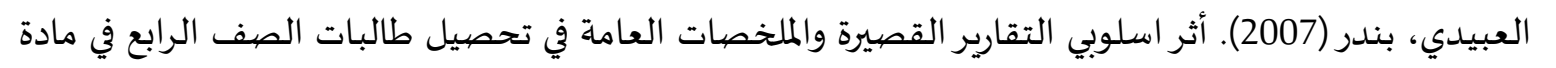

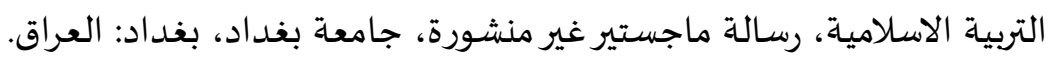

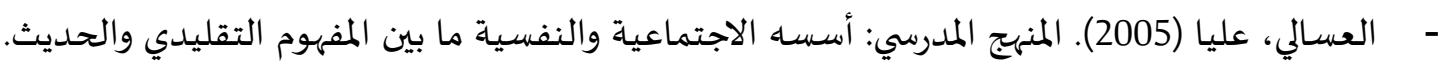
- العيوني، صالح (2003). أثر استخدام أسلوب التعلّم التعاوني على التحصيل في مادة العلوم والاتجاه نحوها

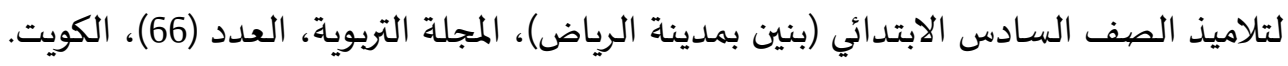


- القرة، على؛ وغوني، جاسم (2004). أثر استخدام الملخصات العامة في تحصيل طلاب الخامس الاساسي في مادة

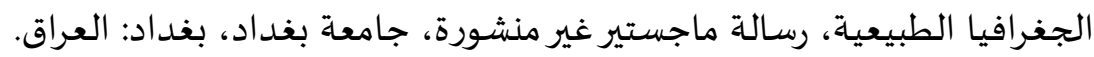

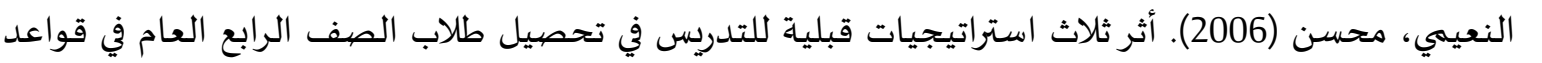

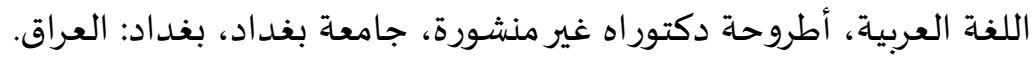

- Colette,M., Jim,b., Lovr,H., Jim,O., \&Jon, S.(2001). National Curriculum Compulsory School Science is it Improving Scientific Literacy?, Educational Resarch.43(2): 189-1999.

- Deng,Z.(2007). Scientific Literacy as an Issue of Curriculum Inquiry, The University of Hong Kong. Promoting Scientific Literacy: Science.

- Bulut, P. (2017). The effect of primary school students' writing attitudes and writing self-efficacy beliefs on their summary writing achievement. International Electronic Journal of Elementary Education, 10(2), 281-285.

- Wilkinson, G. A. (2012). The impact of structured note taking strategies on math achievement of Middle School Students (Doctoral dissertation, Walden University). 